\title{
Market Concentration and Natural Resource Development in Rural America
}

\author{
J. Tom Mueller ${ }^{\mathrm{a}}$, Jesse E. Shircliffa ${ }^{\mathrm{a}}$, Marshall Steinbaum ${ }^{\mathrm{b}}$ \\ ${ }^{a}$ Department of Sociology, Social Work, and Anthropology, Utah State University, Logan, UT 84321, United States \\ ${ }^{b}$ Department of Economics, University of Utah, Salt Lake City, UT 84112, United States
}

\begin{abstract}
Natural resource development, both extractive (oil, gas, mining, timber) and non-extractive (tourism, real estate, outdoor recreation), has been found to negatively impact economic prosperity in rural America. One mechanism recently proposed for why this occurs is high levels of labor market concentration, or oligopsony. Oligopsony occurs when there are few employers within a labor market and can lead to suppressed wages and a power imbalance between employers and workers. In this paper, we test the moderating effect of labor market concentration on the relationship between natural resource development and per capita income and poverty in rural America from 2010 to 2016. By comparing results between extractive and non-extractive development, as well as manufacturing, we show that labor market power attenuates the beneficial relationship observed at low levels of specialization in natural resources - particularly for extractive forms of development. Further, by finding no significant relationship between manufacturing specialization and economic prosperity, nor any moderating effect of labor market concentration in the case of manufacturing, we demonstrate that natural resource development and labor market concentration have a unique relationship with rural American economic prosperity.
\end{abstract}

Keywords: Natural Resources, Oligopsony, Poverty, Market concentration, Dependence

Note: This is the pre-peer review version of a paper that is now available in Rural Sociology. Please find the final revised paper at the following link:

https://onlinelibrary.wiley.com/doi/full/10.1111/ruso.12417 


\section{Introduction}

Rural labor markets, particularly those grounded in natural resource development, are wellknown for being vulnerable and prone to economic hardship (Freudenburg, 1992; Krannich et al., 2014; Lobao et al., 2016; Mueller, 2021a,b). In the United States, rural areas dependent on, or overspecialized in, natural resource development have been found to have elevated levels of poverty, lower incomes, and higher inequality (Douglas and Walker, 2017; Deller and Schreiber, 2012; Freudenburg and Wilson, 2002; Krannich et al., 2014; Lobao et al., 2016; Mueller, 2021a; Perdue and Pavela, 2012). Although prior work on natural resource dependence has mostly focused on extractive activities (e.g., oil, gas, mining, timber), there is an increasing awareness among scholars that nonextractive activities such as tourism, outdoor recreation, real estate, and other forms of natural amenity development can result in negative social and economic outcomes for rural people (Mueller, 2021b; Sherman, 2018; Ulrich-Schad, 2018; Winkler et al., 2012). In this paper, we build upon this growing understanding by evaluating the moderating role of labor market concentration in the relationship between extractive and non-extractive natural resource dependence and economic prosperity.

High levels of labor market concentration, meaning few employers within a given labor market, are detrimental to the economic prosperity of workers through wage suppression and decreased labor power (Azar et al., 2020b; Steinbaum, 2019). Although labor market concentration experienced a recent growth of research attention from economists working on labor markets in general, the topic has received scant attention from those focused specifically on rural people and places. Given that rural labor markets are often concentrated simply due to their size (Azar et al., 2020a), and are frequently dominated by a single large employer (Thiede et al., 2017), the negative impacts posed by oligopsony-meaning a labor market with few employers, and the employer power that goes with it-appear highly relevant to rural scholars, particularly those focused on natural resource development. In-step with this, Mueller (Forthcoming), in his integrative theoretical framework of natural resource dependence, termed dual dependency, argued a key mechanism of natural resource dependence is the local oligopsony formed by natural resource capitalists in the United States. In this paper, we test this conjecture from 2010 to 2016 at the county-level for extractive and nonextractive natural resource-related development. We do so by estimating the non-linear impact 
of each form of development on per capita income and poverty, and then evaluate how that nonlinear relationship changes across the range of market concentration. Further, by also testing these relationships for rural manufacturing, we show that the moderating effect of market concentration appears to be a unique effect for the natural resource sectors.

\section{Background}

\subsection{Market Concentration and Monopsony}

An important element of labor markets is how market structure relates to the relative power of employers versus workers. Paraphrasing Weber $(1971,180)$, power can be defined as the ability to realize one's will "even against the resistance of others." Power can be achieved by various qualitative and structural differences that grant one party an advantage over the other (Burt, 1997). In labor markets, market power is achieved by limiting other parties' ability to "walk away" from an exchange, since the capacity to be selective is crucial to bargaining power (Bowie, 1988). One way employers enjoy market power over workers is to be the sole buyer (or one of few buyers) of labor, known as monopsony and oligopsony, respectively (Steinbaum, 2019; Steinbaum and Stucke, 2019).

Market concentration is achieved when a firm, through mergers, acquisitions, or internal growth, acquires a greater share of the market than other firms, thus the number of firms is reduced and the market is concentrated around those firms (Azar et al., 2020b; Glenna and Cahoy, 2009; Harrigan, 1984). Vertical integration describes when companies expand their control to multiple segments of the commodity chain (Harrigan, 1984). Meat packing industries, for example, vertically integrate by expanding into livestock production and product distribution, allowing companies to reduce risks and negotiate more advantageous contracts with farm laborers (Crabtree, 2016). Horizontal integration, what we examine in this paper, is defined as a single company or small group of companies "gaining greater market share of one segment of a commodity chain" (Glenna and Cahoy, 2009, 114). A rural example of horizontal integration is when larger hospitals purchase smaller hospitals in rural counties, turning them into branches of a single firm rather than independent competitors (Williams et al., 2020). Using vertical or horizontal integration is a common strategy for firms to increase their market share, and as sectors become globalized, firms face pressure to 
gain market share in response to their competitors becoming vertically or horizontally integrated. The result is that firms either seek similar restructuring, or they risk being acquired themselves (Glenna and Cahoy, 2009; Hart and O'Connell, 2006; Herbert and Pritchard, 2004; Heaver et al., 2001; Kudelko et al., 2015). Importantly, we can examine market concentration at multiple scales depending on the question at hand. For instance, we can discuss market concentration in terms of a local labor market as we do in this paper, or in terms of an entire nation, as done elsewhere.

Market concentration is problematic in that it can reduce competition and grant employers asymmetrical control compared to labor (Hafiz, 2019; Steinbaum and Stucke, 2019). In America, horizontal concentration has become a "stylized fact" as there are fewer firms available to purchase labor, pushing local labor markets toward monopsony or oligopsony (Azar et al., 2020b, 13). These changes in America are in-part due to antitrust laws that overemphasize consumer welfare, or the view that price effects are the most meaningful outcome for consumers (Steinbaum and Stucke, 2019). This approach overlooks the fact that increased market concentration comes at a deficit to employees in the form of a lack of competition in the market and decreased bargaining power on the part of employees (Hafiz, 2019; Steinbaum and Stucke, 2019). It is important to note that some proponents of market concentration consider it an effective way to conduct business (Harrigan, 1984). Horizontal mergers and acquisitions may benefit firms, not necessarily employees, through both greater economies of scale and the ability to successfully compete against larger competitors that make similar decisions (Hart and O'Connell, 2006). Still, greater market concentration is generally associated with rising social inequality because as employers gain asymmetrical control, employees have less power to bargain for quality working conditions (Hafiz, 2019). Where there is a lack of employment alternatives, as is common in rural settings, asymmetrical control is associated with degraded labor conditions, as employers shift risks on to employees, curtail pay and benefits, and suppress wages as a means to reduce costs and increase efficiency (Kalleberg, 2011).

Although rural labor markets are often presumed to be fairly concentrated, the majority of the extant work on market concentration has little to say about rural areas. Azar et al. (2020b) show that rural areas experience especially high levels of horizontal integration, and that this is associated with lower wages. However, there is scant other research focused on rural contexts. For instance, Crabtree (2016); Glenna and Cahoy (2009); Hart and O'Connell (2006); and Steinbaum (2019) examine integration and monopsonies among specific sectors, but their analysis does not fo- 
cus on spatial segmentation. In the same time frame that much vertical and horizontal integration practice has increased (from the 1970s and on), rural America has experience significant industrial and economic restructuring (Brown and Schafft, 2019). Given that rural areas have smaller populations and fewer firms compared to urban and suburban geographies, they are more likely to be concentrated by default. In this analysis, we aim to fill this gap in the literature by focusing directly on market concentration in rural America.

\subsection{Natural Resource Development in Rural America}

We center our analysis of rural American labor market concentration in the extant literature on natural resource development and the theoretical framework of dual dependency. Drawing on the work of Mueller (Forthcoming), we divide natural resource development into the categories of extractive (oil, gas, mining, timber) and non-extractive (tourism, outdoor recreation, real estate) development. These two sectors, particularly extraction, have been historically associated with natural resource dependence, or over-specialization in the natural resource sectors (English et al., 2000; Krannich et al., 2014; Mueller, 2021b). This over-specialization is characterized by an association between high levels of natural resource development and low levels of economic prosperity (Freudenburg, 1992; Krannich et al., 2014; Mueller, Forthcoming). Although variable by region and time, elevated levels of extraction in the United States have been associated with lower income, elevated unemployment, higher poverty, and heightened inequality (Freudenburg, 1992; Lobao et al., 2016; Nord and Luloff, 1993; Mueller, 2021a; Perdue and Pavela, 2012; Stedman et al., 2005). Further, although the literature is less-developed than it is for extraction and remains conflicted, high levels of non-extractive forms of natural resource development in rural America have been associated with negative returns to income, elevated poverty, unaffordable housing, and social conflict (English et al., 2000; Ghose, 2004; Hines, 2010; Nelson and Hines, 2018; Mueller, 2021a; Sherman, 2018; Ulrich-Schad, 2018; Ulrich-Schad and Qin, 2018). Although it should be noted that non-extractive activities have been advanced as a boon, or at least not a net harm, to

rural communities in a number of papers grounded in economic growth models (Deller et al., 2001, 2008; Deller, 2010; Marcouiller et al., 2004).

Until recently, there was limited theoretical synthesis regarding the relationship between the outcomes from extractive and non-extractive forms of development. Although many theories had 
been advanced for why extraction is especially harmful to rural economies (see Mueller (Forthcoming) for a full discussion), non-extractive natural resource activities in rural America have had far less theoretical discussion, with much of the theory grounded in basic economic growth models (Deller et al., 2001, 2008; Deller, 2010; Marcouiller et al., 2004). To remedy this lack of cohesion, Mueller (Forthcoming) developed the framework of dual dependency, which we test elements of in this paper. This integrative framework draws on critical theories of capitalism to posit that the root cause of natural resource dependence is the contradiction between the need for capital to be in motion and the spatially static nature of natural resources, termed the spatial contradiction. Due to this contradiction, capitalists in the natural resource sectors face greater friction when attempting to relocate investments than they would in other industries. This contradiction, combined with the ease of external investment in rural areas available to capitalists under American federalism, creates perverse incentives for natural resource capitalists and results in them doubling-down in the locality.

This doubling down is characterized by the natural resource capitalist intentionally inhibiting broad-based economic development and agglomeration, while trying to preserve the highest rate of profit possible (Mueller, Forthcoming). Importantly, both extractive and non-extractive capitalists experience this contradiction - as both are interested in generating profit off of a static resource base. Thus, it is expected that both extractive and non-extractive forms of natural resource development will have an inherently exploitative relationship with rural labor markets, pushing the labor markets into the formation of dual dependencies, the first upon the global capitalist system, and the second upon the resource rich local environment (Mueller, Forthcoming). Within the framework of dual dependency, it is expected that some level of specialization in the natural resource sectors is not inherently bad, and it is likely to result in positive outcomes. It is at high levels of specialization that we expect over-specialization effects (e.g., negative returns) to be more likely (Mueller, 2021a).

Within this framework, Mueller (2021b) identified eight mechanisms by which the spatial contradiction results in adverse economic outcomes. These include disinvestment in education, local elite power, gendered labor markets, low quality jobs, corporate capture of regulatory agencies, temporal variation in markets, low market diversity, and localized oligopsony (e.g., market concentration). The last, localized oligopsony, is our focus in this paper. As stated prior, rural areas have a tendency to face a higher degree of market concentration simply due to the size of the 
population (Azar et al., 2020a). However, in the context of natural resource development, Mueller (2021b) argued this problem will be especially severe. The reason for this is that the economies of scale required to operate in these sectors, particularly extraction, are increasingly infeasible for smaller regional businesses. Due to this, it is easier for external companies to dominate the rural labor market, leading to oligopsony. From this, all of the other deleterious outcomes from elevated market concentration, including wage suppression and inadequate labor power (Azar et al., 2020b; Steinbaum, 2019), work in-concert with the other mechanisms identified to reduce economic prosperity.

Although high levels of labor market concentration are often viewed as being a characteristic only found in extraction (e.g., the company town), non-extractive natural resource capitalists are increasingly operating at large economies of scale which can dominate the labor market of an entire community (Mueller, 2021b). Examples of this include Vail Resorts, which is continuing to apply economies of scale to the ski industry, and Delaware North, which utilizes both horizontal and vertical integration to operate gifts shops and resorts in rural areas (Mueller, 2021b). Given the role of market concentration as a hypothesized mechanism of dual dependency, we expect that higher levels of market concentration will moderate the relationship between natural resource development and economic outcomes. This moderation is expected to result in the relationship between natural resource development and economic outcomes being less dynamic at higher levels of market concentration. This is because we do not expect to see the benefits hypothesized under dual dependency, and partially validated by (Mueller, 2021a), at low levels of development in the case of high market concentration due to wage suppression and diminished labor power.

\subsubsection{Hypotheses}

Our hypotheses for this analysis build from the literature reviewed, the theory presented by (Mueller, Forthcoming), and recent empirical tests conducted by (Mueller, 2021a)—which illustrated important nuance initially lacking in the theoretical arguments by Mueller (Forthcoming). Modeling the relationships between natural resource development and economic outcomes as nonlinear (i.e., quadratic) from 2000 to 2015, Mueller (2021a) found evidence of overspecialization, on average, at high levels of extraction-particularly in remote rural counties. In the case of non-extractive development, Mueller (2021a) did not find the expected relationship, which he hy- 
pothesized would be similar to extraction. Instead, Mueller (2021a) found that non-extractive development generally resulted in negative economic outcomes across the range of development, with the returns variously improving or getting worse across the range of development dependent on outcome. Importantly, this unexpected finding did not disprove the arguments laid out in the framework of dual dependency, but rather provided important evidence that we cannot expect identical patterns of over-specialization between extractive and non-extractive development just because they share the spatial contradiction. Relying on the outlined literature, our formal hypotheses in this analysis are as follows:

Hypothesis 1: Extractive natural resource development will have a non-linear relationship with income and poverty, wherein the beneficial relationship at low levels of development diminish and ultimately become negative.

Hypothesis 1.1: As market concentration increases, the initial beneficial results of development at low levels of development will be reduced, resulting in a more consistent, and less beneficial, relationship.

Hypothesis 2: Non-extractive development will have a non-linear relationship with income and poverty, wherein the relationship, which may or may not be beneficial at low levels, will become less beneficial as the absolute level of development increases.

Hypothesis 2.1: As market concentration increases, the initial beneficial results of development at low levels of development will be reduced, resulting in a more consistent, and less beneficial, relationship.

\subsection{Manufacturing and Comparison Hypothesis}

Although the focus of our analysis, and guiding theoretical framework, is related to natural resource development, we also assess the relationship between manufacturing and economic outcomes in this study. This decision was made due to a limited amount of direct comparison between natural resource sectors and non-natural resource sectors in the literature on natural resource dependence. Thus, it remains an empirical question if the overspecialization we expect for natural resource-related industries is truly unique, or just a common pattern of overspecialization more often evaluated by natural resource scholars. Manufacturing is a valuable sector for this comparison 
due to its rich history and presence in rural American labor markets (Brown and Schafft, 2019; Thiede and Slack, 2017). Manufacturing in rural America has ebbed and flowed over the past 50 years. In the 1970s and 1980s there was a boom in rural manufacturing which rejuvenated much of rural America as jobs in manufacturing exited urban areas for more desirable economic contexts in rural regions (Lovejoy and Krannich, 1982; Thiede and Slack, 2017). Unfortunately, the boom of the 1980s was more short-lived than many had hoped. As globalization proceeded, many manufacturing jobs which initially relocated from urban to rural America, ultimately relocated overseas. As evidenced by this migration of the capitalist investment, manufacturing represents a sector more detached from the spatial contradiction than the natural resource sectors. Instead of doubling down, we see the spatial fix described by Harvey (2018:1982) and Smith (1984)—wherein firms relocated to avoid crises of overaccumulation and labor market power (Smith, 1984, 2011) — operating as expected. From this history, we expect that over-specialization is unlikely in the manufacturing sector. This is because the perverse incentives which cause natural resource capitalists to double down in rural areas do not exist within the manufacturing sector. Thus, any manufacturing remaining in a rural area from 2010 to 2016 likely has a reason to do so and is expected to have a simply beneficial, and relatively stable, relationship with economic outcomes across the range of manufacturing development. The formal hypothesis for this comparative case is as follows:

Hypothesis 3: Manufacturing will have a steady positive relationship with economic outcomes, wherein growth in manufacturing is associated with positive returns to economic indicators.

Hypothesis 3.1: Although over-specialization is not expected, the benefits of manufacturing will still be reduced at higher levels of market concentration.

\section{Methods}

\subsection{Data}

Data for this study were collated from six different sources to make a county level dataset for the United States from 2010 to 2016. Demographic data and poverty rates were taken from the 2010 Census, as well as the American Community Survey (ACS) five-year estimates for each wave from 2008-2012 to 2014-2018. For each year of the data, five year estimates were centered on the mid-year 
(e.g., 2010-2014 is treated as 2012). Census and ACS data, along with a corresponding shapefile were extracted from the National Historical Geographic Information System (NHGIS; Manson et al. (2020)). Data for per capita income and total county employees were extracted from the Bureau of Economic Analysis (BEA) Local Area Personal Income and Employment data (Bureau of Economic Analysis, 2020). Our data on county-level industry employment was extracted from the Imputed County Business Patterns Database developed by Eckert et al. (2020). Our county-level measures of labor market concentration were computed from the database of online job postings produced by Burning Glass Technologies (Burning Glass, 2020). Finally, we use USDA Economic Research Service Rural Urban Continuum Codes (RUCC) for our measure of rurality (Economic Research Service, 2020). Due to boundary changes and idiosyncrasies between the way each data

source managed certain types of county-level units (e.g., the independent cities of Virginia), a number of counties were merged into time-consistent geographic units in both our quantitative database and our shape file. Further, with the exception of Hawaii-which is all islands-the three island counties within continental states were merged into their nearest inland neighbor to facilitate spatial econometrics. All county boundary changes are detailed in the appendix (Table A1). In our base models no data is missing, with the exception of a single 2016 observation of a New Mexico county where poverty data was not reported by the Census. In our market concentration models, a significant number of county-year observations were missing because their market concentration was unidentifiable. This is detailed further below.

\subsection{Dependent Variables}

In line with prior work in this area, to ensure our analysis captured an aggregate measure of income, as well as the distribution of that income, we assess two dependent variables: per capita income and poverty (Lobao et al., 2016; Mueller, 2021a). Per capita income, extracted from Bureau of Economic Analysis (2020), is adjusted for residence. This means that our dependent variable is not the per capita income of all income generated in a county, but is instead the per capita income which went to residents of the county. This decision was made so that our dependent variables reference the same population, while also more fully capturing the theory being testedwhich emphasizes impacts to residents (Mueller, Forthcoming). Per capita income was calculated by dividing the total income to residents reported by the Bureau of Economic Analysis (2020) 
in thousands by the census total population reported for the corresponding period. Poverty rate was calculated by dividing the population determined as being below the poverty line by the total population for whom poverty status was determined and multiplying by 100 as reported by NHGIS (Manson et al., 2020).

\subsection{Independent Variables of Interest}

\subsubsection{Employment Share}

We operationalize the level of development in a sector via employment share. Employment share was calculated for the three sectors outlined prior: Natural resource extraction, non-extractive natural resource activities, and manufacturing. To calculate employment shares in each sector, the total number of employees estimated in each sector by Eckert et al. (2020) was divided by the total number of workers within the county reported by the BEA for the equivalent year and multiplied by 100. Industries were determined by evaluating the relevant North American Industrial Classification System codes and selecting those appropriate to hypothesis testing. In-line with prior work Mueller (2021a,b), extraction was comprised of forestry and logging (NAICS=113); support activities for forestry (NAICS=114); fishing, hunting, and trapping (NAICS=1153); and mining, quarrying, and oil and gas (NAICS=21). Non-extractive activities included arts, entertainment, and recreation $(\mathrm{NAICS}=71$ ); accommodation and food services (NAICS=72); scenic sightseeing and transportation; and real estate and rental and leasing (NAICS=531). Manufacturing was comprised of the general County Business Patterns manufacturing grouping (NAICS=31).

\subsubsection{Market Concentration}

Market concentration was computed using the Herfindahl-Hirschmann Index (HHI) (Azar et al., 2020b). This index, scaled from 0 to 1 , where 0 means no market concentration and 1 means complete market concentration, indicates the level of concentration found within an industry in a labor market. For any given market, the HHI is computed as

$$
H H I=\sum_{i}^{N} s_{i}^{2}
$$

where $s_{i}$ is the market share of firm $i$, and those shares are squared and summed across all active firms. Similar to Azar et al. (2020a), we calculate HHI using online job vacancy data from 
Burning Glass, a market research firm that tracks online job announcements, and who posts those announcements, across the country.

For our purposes of this analysis, the geographic labor market used to estimate HHI is the county. Although labor markets may extend beyond county boundaries (Fowler and Jensen, 2020), the likelihood of workers applying to a given job diminishes strongly in distance. According to one estimate, $50 \%$ of all job applications are made to employers located in the county where the applicant lives (Marinescu and Rathelot, 2018). Further, our use of spatial econometrics, detailed below, captures the spillover effects of concentration occurring across county boundaries.

For the industry dimension of market concentration, we use three "super-industries": natural resource extraction, non-extractive economic development (e.g., tourism), and manufacturing. For each super-industry, we collapse all job postings from each NAICS sector within that superindustry. ${ }^{1}$ From these pooled groups of vacancies, we then estimated an upper and lower-bound HHI for each super-industry. The bounds refer to the assignment of vacancies whose employer is not identified: either individually to separate firms (corresponding to lower-bound HHI), or all to the same firm (upper-bound HHI). We use the lower bound in our analysis.

Given this approach, job openings had to be posted for a market concentration to be calculated. If no job openings were posted in a given county-super industry-year, then the market concentration is not defined. We only include defined observations in all models. Due to this, we only include 11,522 county-year observations in our market concentration model of income and 11,521 in our model of poverty. It is important to acknowledge that the greatest percentage of missing observations was for the most rural counties. A total of $70.24 \%$ of metropolitan county-year observations had identified HHIs for all three sectors, compared to $47.65 \%$ of non-metropolitan metro-adjacent and $37.73 \%$ non-metropolitan remote counties. Although this means we are not capturing all of rural America in these models, it is the best data on the topic known to us at this time. Given the importance of understanding market concentration in rural America and the fact that our fixed

\footnotetext{
${ }^{1}$ For the extractive super-industry, the NAICS codes are 113, 114, 1153, and 21. For the non-extractive, the NAICS codes are $72,71,531$, and 487. For manufacturing, they are 31,32 , and 33 . These are larger industries than has been typical in the literature on labor market concentration that uses industry-based market definitions, yielding lower (more conservative) estimates of concentration that likely over-estimate the degree to which workers in a sector can or typically do cross or consider crossing market boundaries (Benmelech et al., 2020).
} 
effects model specification attenuates some of the bias this imposes, we believe using this data, while acknowledging its weaknesses, is better than not asking the question at all.

\subsubsection{Time-Variant Control Variables}

Although our use of time and period fixed effects removes bias imposed by time-invariant counfounders, it does not account for those counfounding factors which vary over time. To account for this, we employ the same control variables used by (Mueller, 2021a). These factors are expected to influence both our economic outcome variables and our independent variables of interest and include total population - expected to lead to lower levels of extraction and greater economic prosperity (Johnson and Lichter, 2019); percent of the population over the age of 65 - which can either decrease extractive natural resource development and economic prosperity through aging in place (Thiede et al., 2017), or increase non-extractive development and economic prosperity through amenity migration (Poudyal et al., 2008); and percent of the population which is white, Black, and Latino/a - expected to capture the counfounding effects of ethnoracial concentration which can impact the form and level of development and economic prosperity due to deep-seated racism (Duncan, 2014; Harvey, 2017), labor market discrimination, and linked migration patterns between Latino/a immigrants and amenity migrants (Nelson et al., 2009).

\subsubsection{Rural Indicator}

The interest of our analysis is rural counties. However, rurality is not a simple dichotomy. In reality, rurality is a continuum which is notoriously difficult to capture (Isserman, 2005; Schroeder et al., 2019). To ensure we both capture some degree of this continuum, while still providing an interpretable analysis, we use a three-category rural indicator. This indicator, generated via the RUCC codes (Economic Research Service, 2020), classifies counties as either Metropolitan, NonMetropolitan Metro-Adjacent, or Non-Metropolitan Remote (e.g., not adjacent to a metropolitan area).

\subsection{Analytic Approach}

We evaluate our hypotheses using Spatial lag of X (SLX) models with both period and unit fixed effects with cluster-robust standard errors (Cameron and Miller, 2015; Vega and Elhorst, 2015). It was necessary to use a spatial econometric model due to the permeable nature of county boundaries 
and the spatial clustering of social factors in the United States (Brooks, 2019; Chi and Zhu, 2019; Lobao et al., 2007a,b; Thiede et al., 2018). We use the SLX model, which is a local spillover specification including spatial lags of all independent variables, due to the recommendations of Vega and Elhorst (2015). This model is desirable because it can be estimated via conventional OLS regression techniques, can handle the non-linear effects we model, and is easily interpretable (Gibbons and Overman, 2012; Vega and Elhorst, 2015). Unlike more complicated spatial models, in an SLX model, the direct relationship is simply $\beta$ and the indirect relationship is simply $\theta$ (Vega and Elhorst, 2015).

To estimate the effects of interest, a series of quadratic terms and interactions were included in our models. For each outcome, we first estimate a base model which evaluates the non-linear within-county relationship between each form of development and the outcome of interest. The non-linear effect is specified as quadratic due to the underlying hypothesis of over-specializationwherein the effects of development is expected to diminish at higher levels (Mueller, Forthcoming, 2021a). Although we do not expect manufacturing to have similar over-specialization effects as natural resources, we model it in the same way to explicitly test this conjecture.

We isolate the effect for non-metropolitan metro-adjacent and non-metropolitan remote counties by interacting our three-category variable with the independent variables of interest, resulting in a simple spatial-regime approach (Chi and Zhu, 2019). This approach allows us to extract the direct effect of each form of development for each of the three types of counties. Although metropolitan effects are estimated, we do not report them in the results due to their irrelevance to study hypotheses.

The full base model is presented in Equation 2, where $y_{i t}$ is the outcome of interest for county $i$ at time $t$, metro is the three-category indicator of metropolitan status, $e x_{i t}$ is the employment share in extraction, $n x_{i t}$ is the employment share in non-extractive natural resource activities, $\operatorname{man}_{i t}$ is the employment share in manufacturing, $X$ is a vector of time variant controls, $W$ is a first-order queen's contiguity spatial weights matrix, $\beta$ is the direct relationship between an independent variable and the outcome, $\theta$ is the indirect relationship between an independent variable and the outcome, and $u_{i t}$ represent the error in model captured by the unit fixed effect, $\mu_{i}$, the period fixed effect $c_{t}$, and stochastic error, $\epsilon_{i t}$. 


$$
\begin{aligned}
y_{i t} & =\text { metro } *\left[\beta_{1} e x_{i t}+\beta_{2} e x_{i t}^{2}\right] \\
& + \text { metro } *\left[\beta_{3} n x_{i t}+\beta_{4} n x_{i t}^{2}\right] \\
& + \text { metro } *\left[\beta_{5} \operatorname{man}_{i t}+\beta_{6} \operatorname{man}_{i t}^{2}\right. \\
& +W \theta_{1} e x_{i t}+W \theta_{2} e x_{i t}^{2} \\
& +W \theta_{3} n x_{i t}+W \theta_{4} n x_{i t}^{2} \\
& +W \theta_{5} \operatorname{man}_{i t}+W \theta_{6} \operatorname{man}_{i t}^{2} \\
& +\beta_{7} X_{i t}+W \theta_{7} X_{i t}+u_{i t} \\
u_{i t} & =\mu_{i}+c_{t}+\epsilon_{i t}
\end{aligned}
$$

After estimating the base model, we estimate our full models by introducing market concentration in the form of HHI. As seen in Equation 3, the super-industry-specific HHI, $C$ is interacted with the relevant employment share terms to test our hypotheses regarding the detrimental effect of market concentration.

$$
\begin{aligned}
y_{i t} & =\text { metro } *\left[\left(\beta_{1} e x_{i t}+\beta_{2} e x_{i t}^{2}\right) * C_{e x}\right] \\
& + \text { metro } *\left[\left(\beta_{3} n x_{i t}+\beta_{4} n x_{i t}^{2}\right) * C_{n x}\right] \\
& + \text { metro } *\left[\left(\beta_{5} \operatorname{man}_{i t}+\beta_{6} \operatorname{man}_{i t}^{2}\right) * C_{m a n}\right] \\
& +\left(W \theta_{1} e x_{i t}+W \theta_{2} e x_{i t}^{2}\right) * C_{e x} \\
& +\left(W \theta_{3} n x_{i t}+W \theta_{4} n x_{i t}^{2}\right) * C_{n x} \\
& +\left(W \theta_{4} n x_{i t}+W \theta_{5} n x_{i t}^{2}\right) * C_{m a n} \\
& +\beta_{7} X_{i t}+W \theta_{7} X_{i t}+u_{i t} \\
u_{i t} & =\mu_{i}+c_{t}+\epsilon_{i t}
\end{aligned}
$$

Due to the difficulties in interpretation posed by our models due to non-linear effects and threeway interactions, we present our results visually via estimates of the marginal direct relationships between independent variables of interest and outcomes. Thus, full tables of regression output are not included in this manuscript, but are available in the online supplement (Table A3). We 
estimate our base marginal effects across a constrained range of employment shares for all three forms of development. Effects are estimated across a range which contains the vast majority of observations for all three forms - all integers from 0 to 30 (Mueller, 2021a). Finally, to evaluate the impact of HHI, we re-estimate our base marginal effect with HHI held at 0.25, 0.5, 0.75, and 1. From this, hypotheses are evaluated by assessing the changing values of the direct relationships, and the overlap of the $95 \%$ confidence intervals of estimates with zero.

\section{Results}

\subsection{Descriptive Results}

For the sake of brevity, we only present summary statistics for non-metropolitan counties here. Summary statistics for metropolitan counties and all counties combined are available in the online supplement. As seen in Table 1, manufacturing had a greater average employment share over the study period from 2010 to 2016 than either form of natural resource development. Further, nonextractive natural resource-related development played a much more significant role in both forms of non-metropolitan counties than extraction, on average. When considering market concentration, the most heavily concentrated form of development, on average, was extraction. This was then followed by manufacturing and non-extractive activities.

\subsection{Base Models}

Here we will first present both base models, and then present the results for market concentration models. Results from our base models are shown in Figures 1 and 2. Increases in extraction were initially associated with increases in income and decreases in poverty, but these relationships diminished as employment share grew. In-line with prior work, these effects were more visible in remote non-metropolitan counties than those that were metro-adjacent (Mueller, 2021a). Nonextractive development had a less significant relationship than expected. Although the trends of non-linearity were similar to those found by Mueller (2021a), the relationship was only consistently significantly different than zero in the case of per capita income in remote counties. Finally, manufacturing countered expectations of beneficial relationships by displaying stable relationships not significantly different than zero in all but the case of per capita income and remote counties, where over-specialization effects were visible. 
Table 1: Summary Statistics for Model Variables

\begin{tabular}{lcccc}
\hline \hline & Mean & SD & Min & Max \\
\hline Nonmetropolitan Remote (N =941) & & & & \\
\hline Per Capita Income to Residents (thousands) & 22.81 & 9.95 & 6.69 & 101.14 \\
Poverty Rate & 16.82 & 7.19 & 1.51 & 55.10 \\
Extractive Employment Share & 1.78 & 3.79 & 0.00 & 60.48 \\
Non-extractive Employment Share & 5.80 & 4.78 & 0.00 & 55.61 \\
Manufacturing Employment Share & 6.52 & 7.91 & 0.00 & 86.63 \\
HHI - Extraction & 0.78 & 0.29 & 0.05 & 1.00 \\
HHI - Non-extractive & 0.41 & 0.31 & 0.01 & 1.00 \\
HHI - Manufacturing & 0.55 & 0.32 & 0.03 & 1.00 \\
Population (thousands) & 16.75 & 17.80 & 0.07 & 197.66 \\
Percent Over 65 & 18.82 & 4.96 & 3.79 & 39.16 \\
Percent white & 86.30 & 17.16 & 3.11 & 100.00 \\
Percent Black & 5.59 & 12.93 & 0.00 & 77.46 \\
Percent Latino/a & 8.88 & 14.73 & 0.00 & 95.54 \\
\hline Non-metropolitan Metro-Adjacent (N =1,020) & & & & \\
\hline Per Capita Income to Residents (thousands) & 19.79 & 5.95 & 1.27 & 127.41 \\
Poverty Rate & 17.95 & 6.42 & 0.00 & 53.95 \\
Extractive Employment Share & 1.27 & 2.89 & 0.00 & 36.33 \\
Non-extractive Employment Share & 6.20 & 4.09 & 0.00 & 68.87 \\
Manufacturing Employment Share & 9.85 & 7.91 & 0.00 & 74.28 \\
HHI - Extraction & 0.81 & 0.27 & 0.04 & 1.00 \\
HHI - Non-extractive & 0.34 & 0.27 & 0.00 & 1.00 \\
HHI - Manufacturing & 0.48 & 0.30 & 0.01 & 1.00 \\
Population (thousands) & 29.79 & 23.78 & 0.60 & 189.28 \\
Percent Over 65 & 17.96 & 3.73 & 4.58 & 38.82 \\
Percent white & 84.01 & 17.38 & 3.55 & 100.00 \\
Percent Black & 9.77 & 16.17 & 0.00 & 87.41 \\
Percent Latino/a & 8.05 & 13.59 & 0.00 & 99.18 \\
\hline \hline
\end{tabular}




\section{Extractive Development and Income}
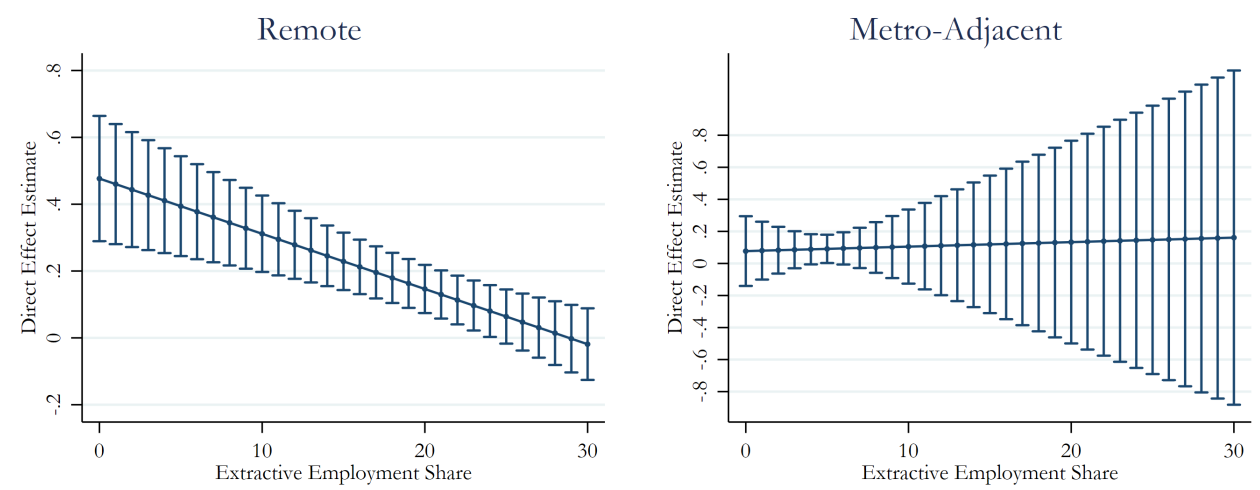

Non-extractive Development and Income
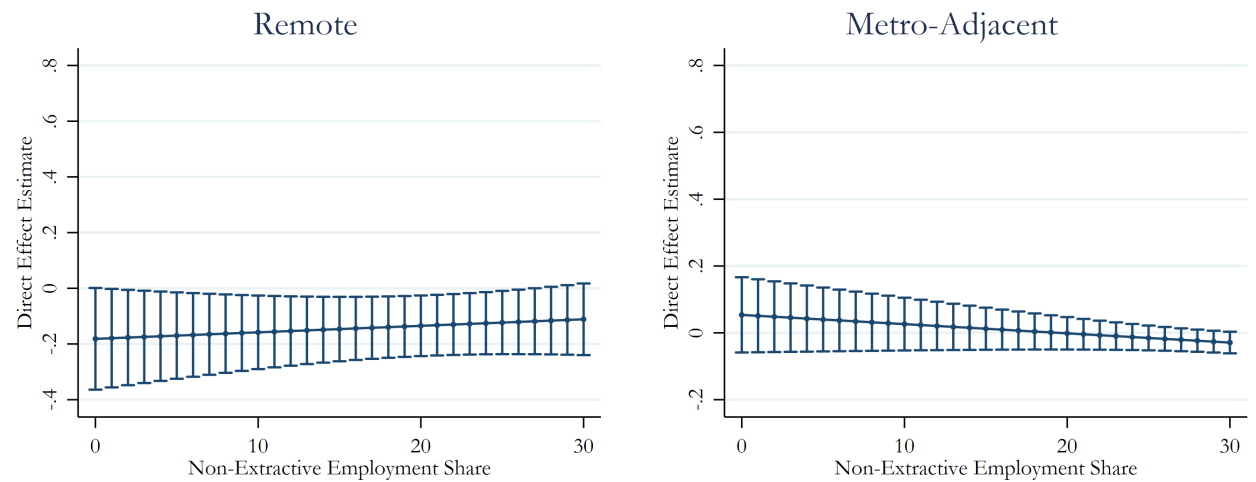

\section{Manufacturing Development and Income}
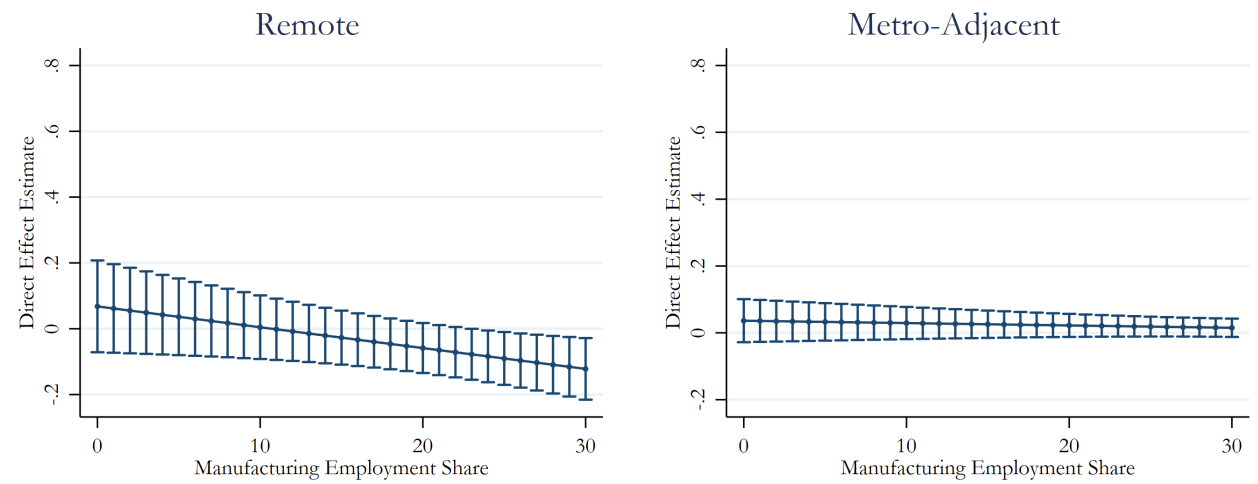

Figure 1: Base model results for per capita income. Predicted marginal direct relationships for per capita income across constrained ranged of employment share. Other variables held constant at means. Vertical bars represent $95 \%$ CI. 


\section{Extractive Development and Poverty}
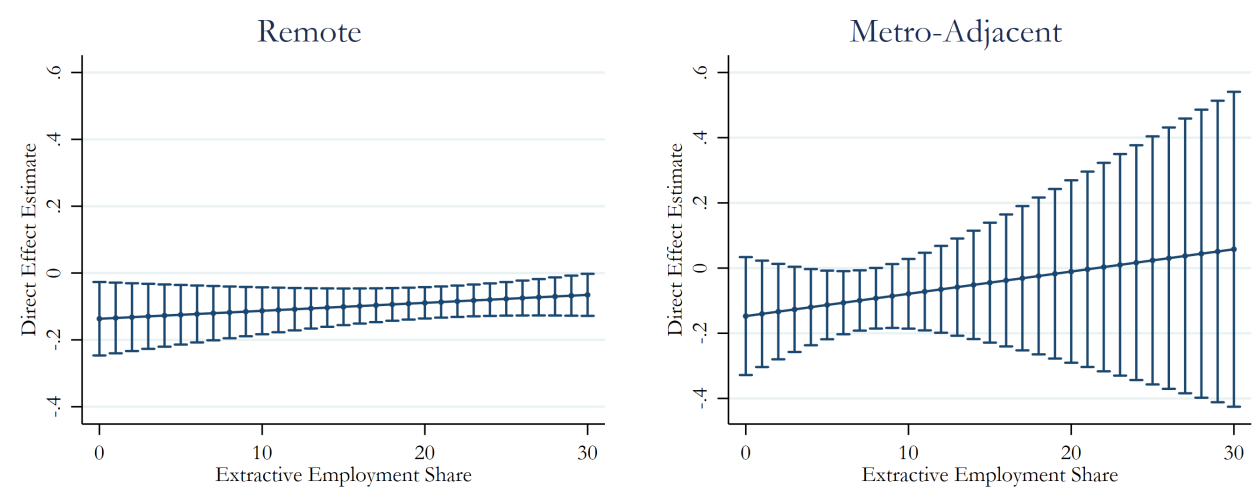

Non-extractive Development and Poverty
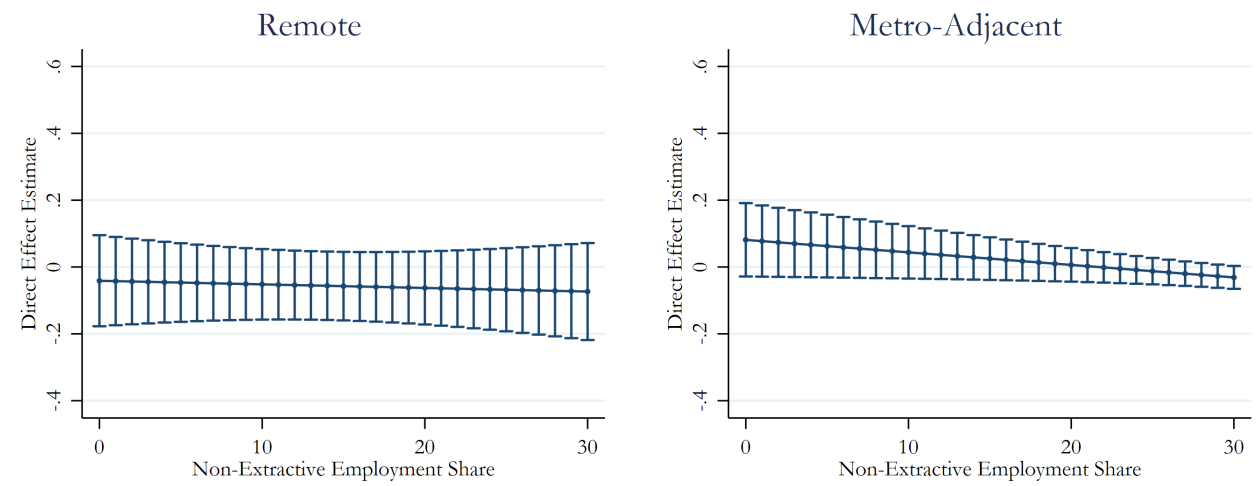

Manufacturing Development and Poverty
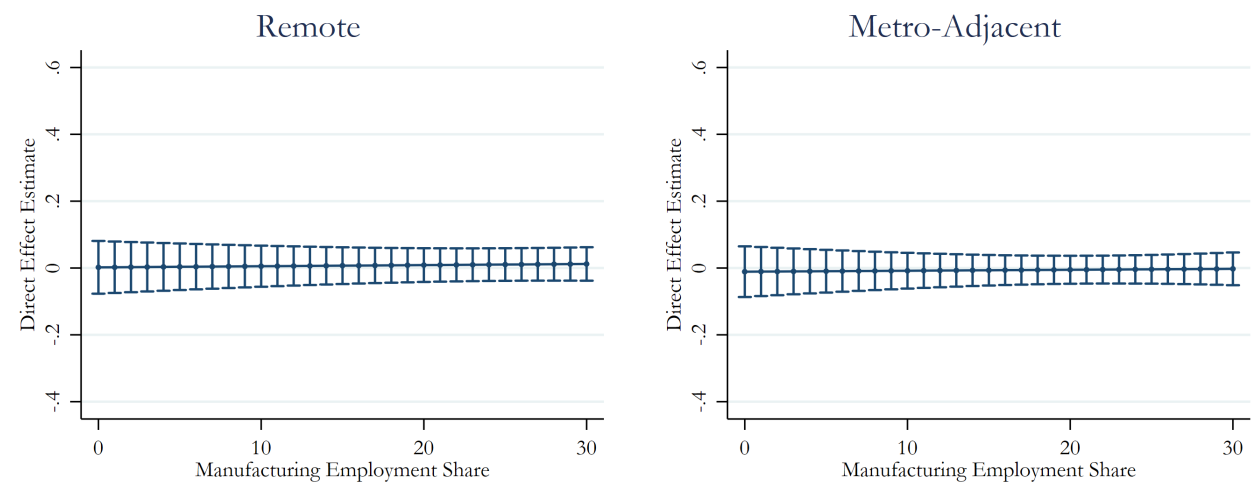

Figure 2: Base model results for poverty. Predicted marginal direct relationships for poverty across constrained ranged of employment share. Other variables held constant at means. Vertical bars represent $95 \%$ CI. 


\subsection{Market Concentration Models}

\subsubsection{Extraction}

Results for our market concentration models of extraction are presented in Figures 3 through 6. Across both the income and poverty models, results generally support the market concentration specific hypothesis for extractive development. In three of the four figures we can see that the the initially beneficial relationship between development and economic outcomes observed at low absolute levels of development diminished, and the overall relationship became more constant, as HHI rose. This effect was not observed for the relationship between extraction and income in metro-adjacent counties.

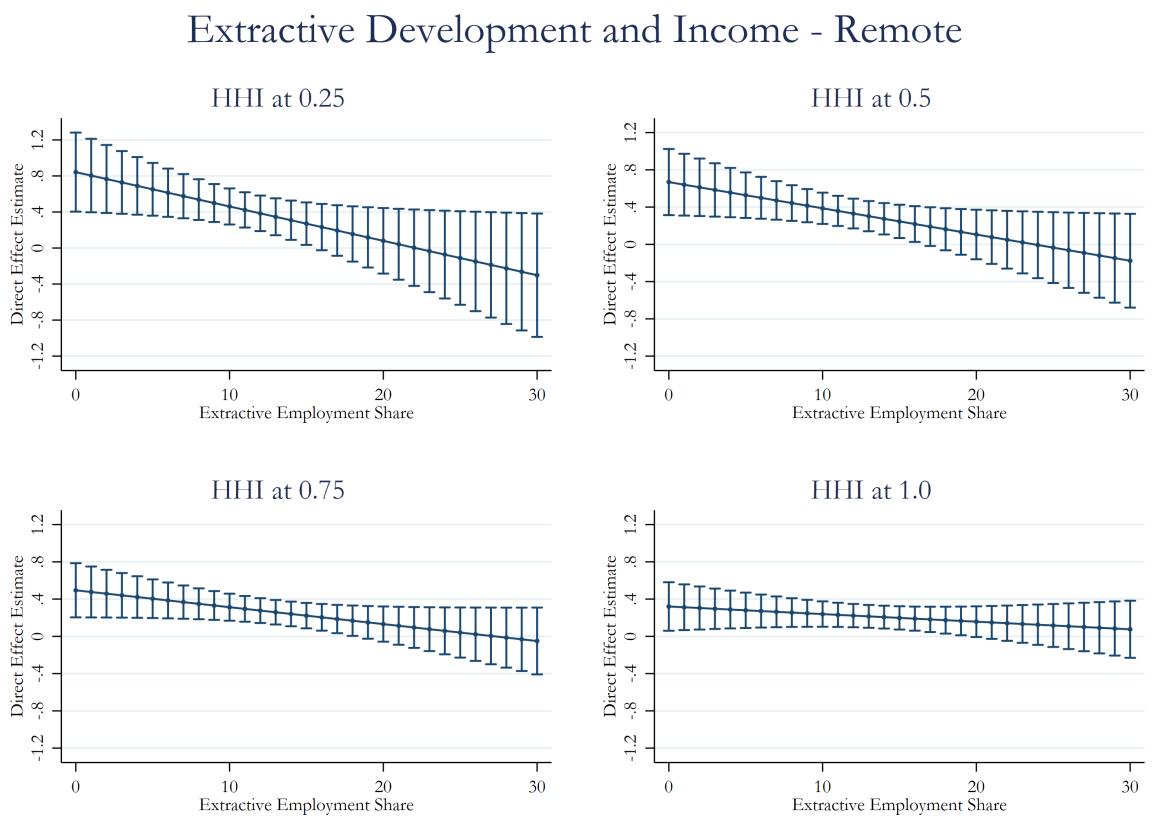

Figure 3: Predicted marginal direct relationships for per capita income across constrained ranged of extractive employment share in remote counties. Other variables held constant at means. Vertical bars represent $95 \%$ CI. 


\section{Extractive Development and Income - Metro Adjacent}
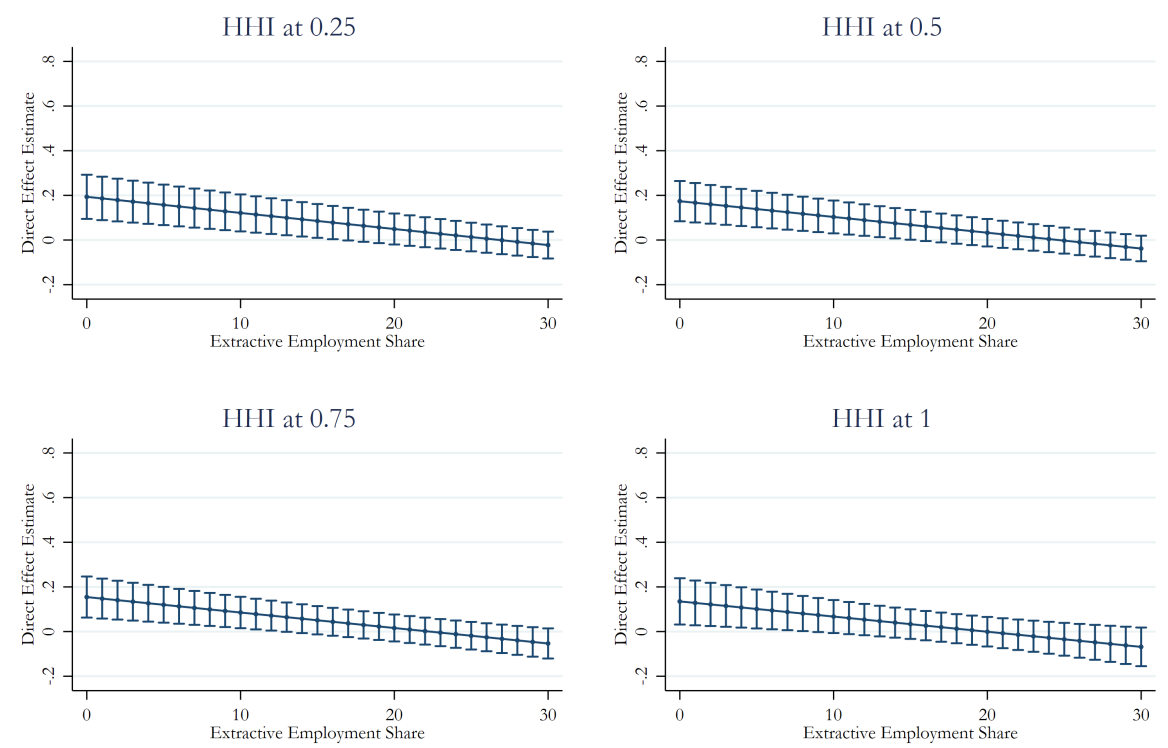

Figure 4: Predicted marginal direct relationships for per capita income across constrained ranged of extractive employment share in metro-adjacent counties. Other variables held constant at means. Vertical bars represent $95 \%$ CI.

\section{Extractive Development and Poverty - Remote}
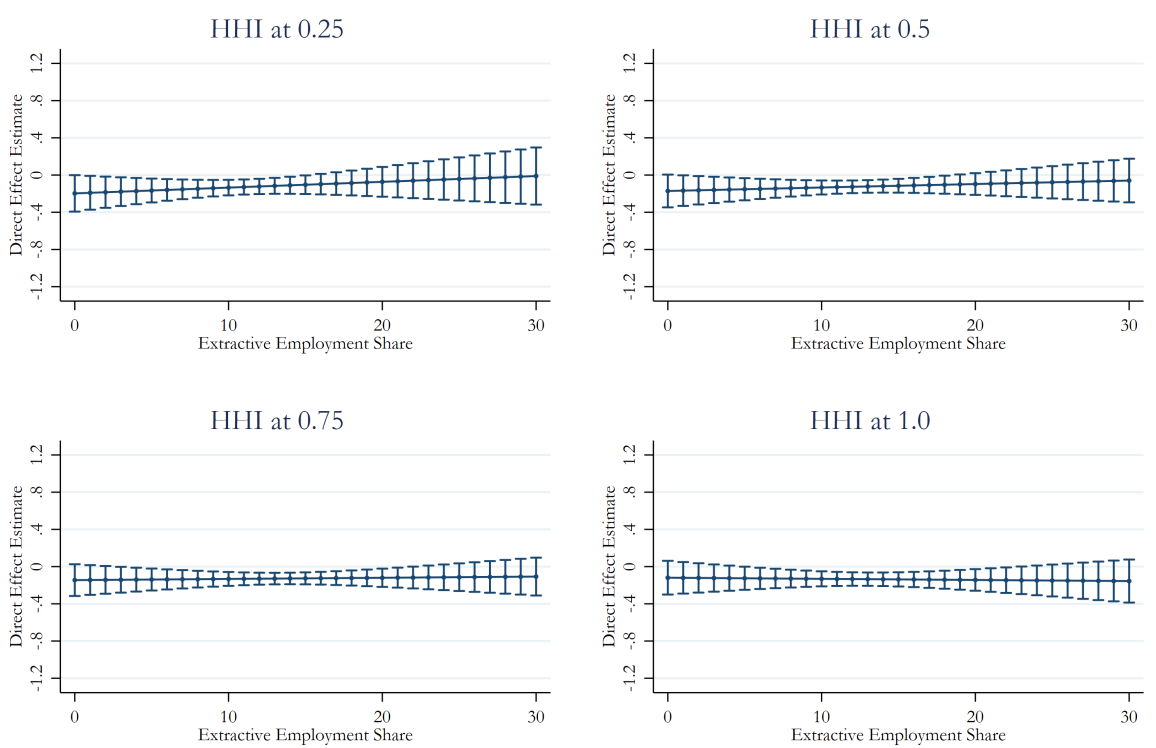

Figure 5: Predicted marginal direct relationships for poverty across constrained ranged of extractive employment share in remote counties. Other variables held constant at means. Vertical bars represent 95\% CI. 


\section{Extractive Development and Poverty - Metro Adjacent}
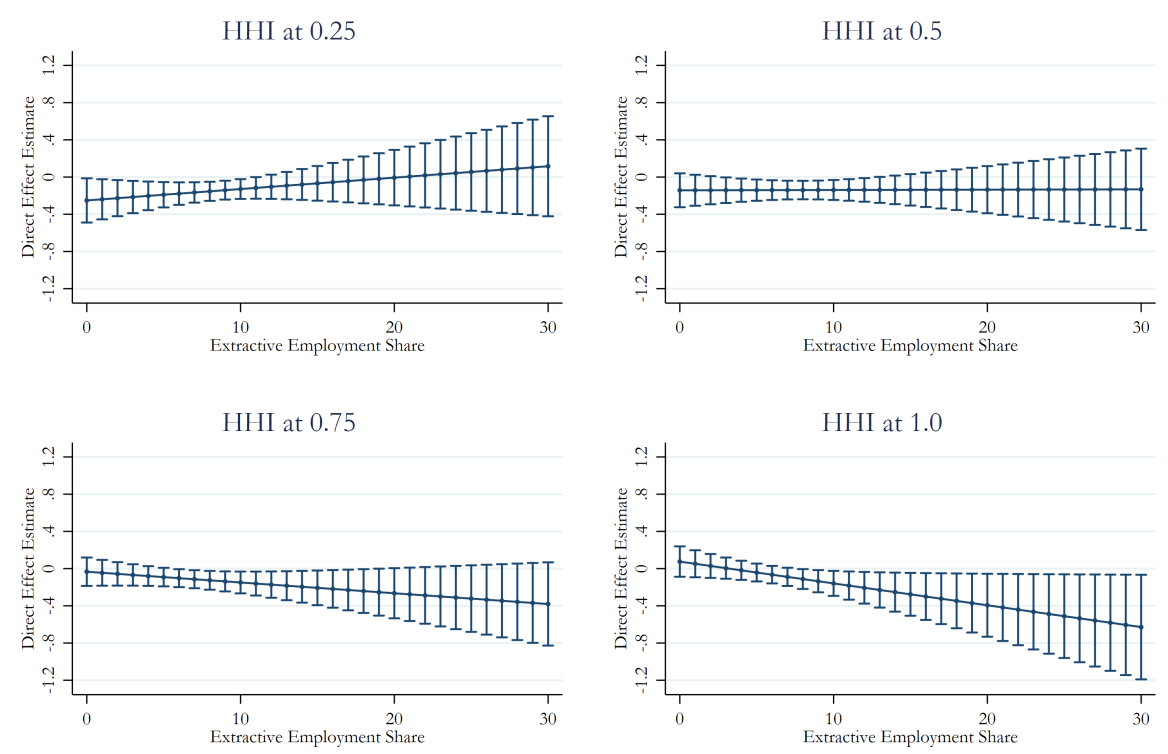

Figure 6: Predicted marginal direct relationships for poverty across constrained ranged of extractive employment share in metro-adjacent counties. Other variables held constant at means. Vertical bars represent $95 \%$ CI.

\subsubsection{Non-extractive Natural Resource Development}

When looking at non-extractive natural-resource related development (Figures 7 to 10), we do see some curves flatten, supporting our hypothesis, which argued the relationship between non-extractive development and economic outcomes would become more stable over the range of development as HHI increased due the relationship being more negative at all levels of development. This moderating effect was visible in the case of per capita income in metro-adjacent counties and poverty in remote counties, but not the other two scenarios. Although we do see some evidence of moderation, the relationships were generally not significantly different than zero, indicating limited support of hypotheses. 
Non-Extractive Development and Income - Remote
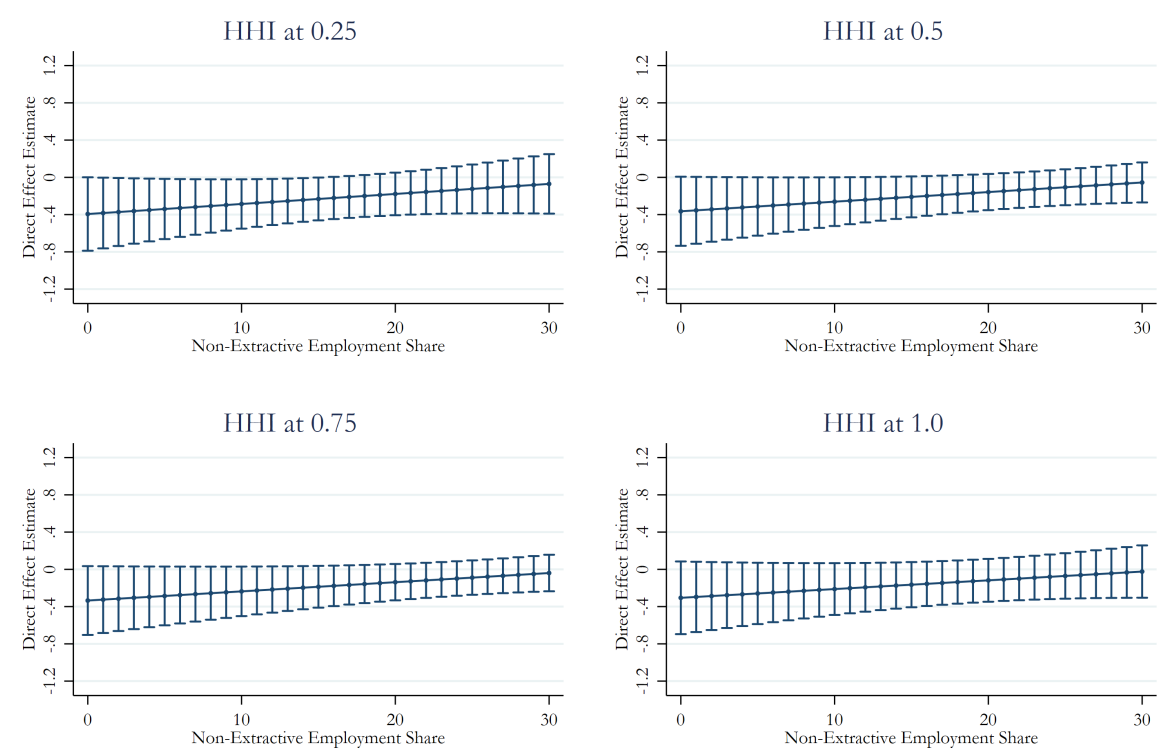

Figure 7: Predicted marginal direct relationships for per capita income across constrained ranged of non-extractive employment share in remote counties. Other variables held constant at means. Vertical bars represent $95 \%$ CI.
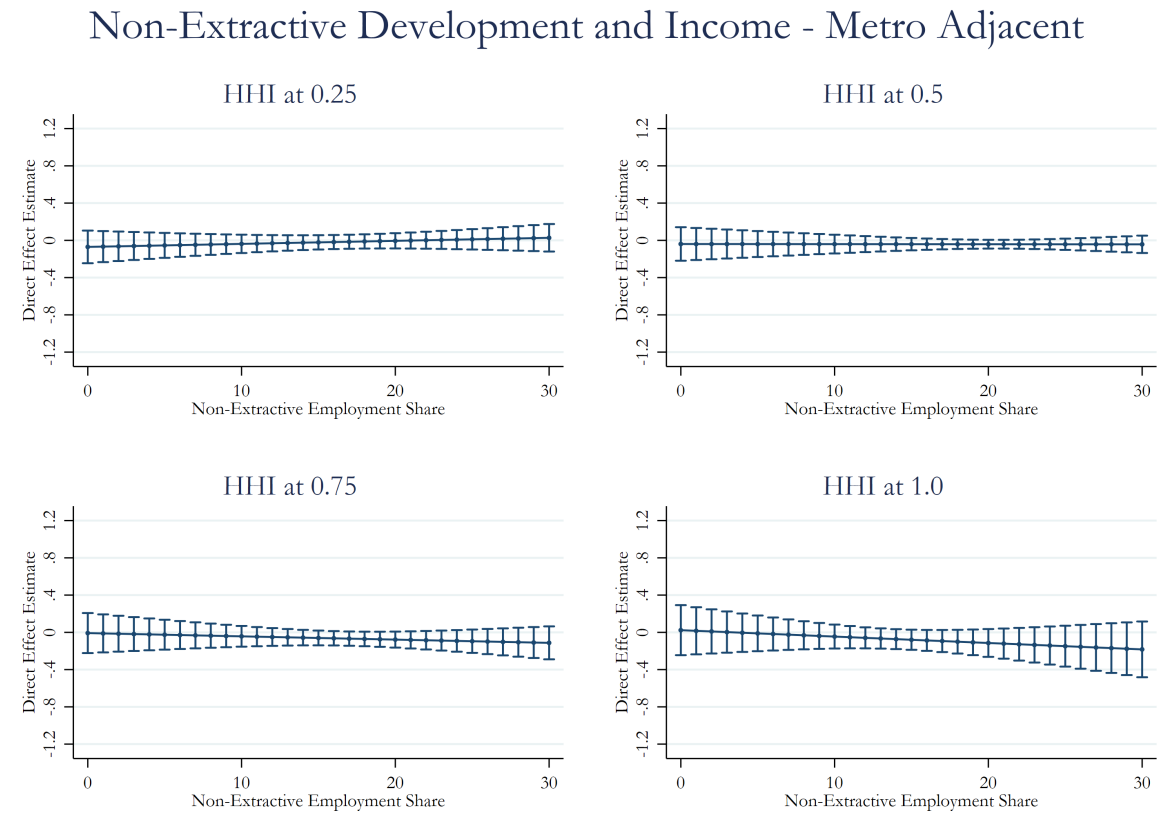

Figure 8: Predicted marginal direct relationships for per capita income across constrained ranged of non-extractive employment share in metro-adjacent counties. Other variables held constant at means. Vertical bars represent $95 \%$ CI. 
Non-Extractive Development and Poverty - Remote
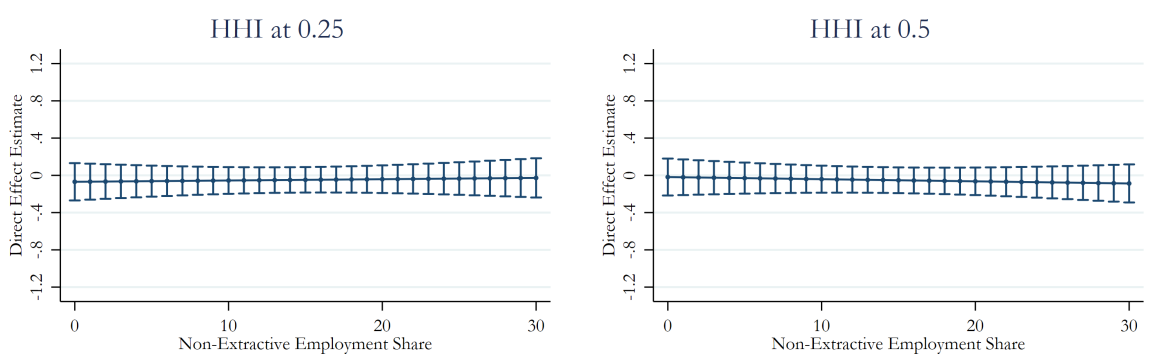

HHI at 0.75
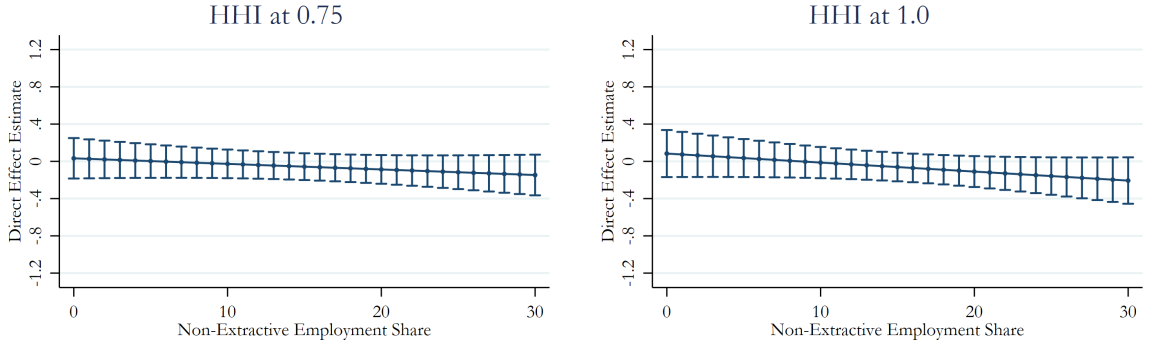

Figure 9: Predicted marginal direct relationships for poverty across constrained ranged of non-extractive employment share in remote counties. Other variables held constant at means. Vertical bars represent 95\% CI.

Non-Extractive Development and Poverty - Metro Adjacent
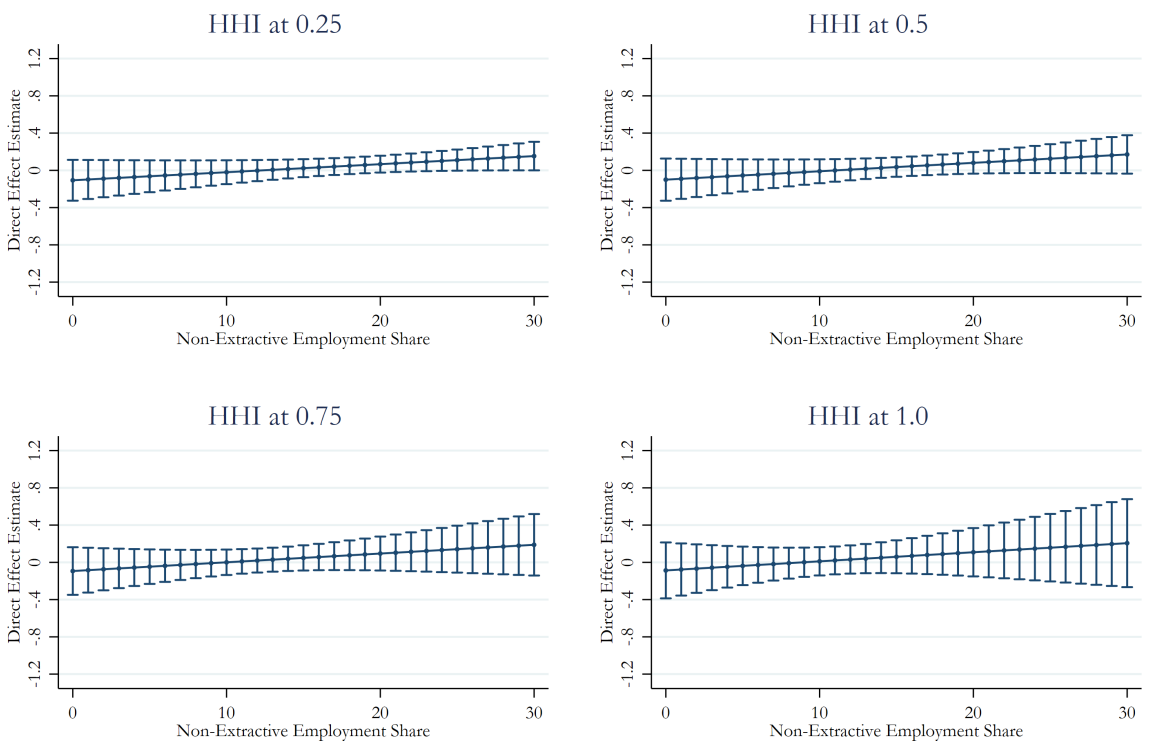

Figure 10: Predicted marginal direct relationships for poverty across constrained ranged of non-extractive employment share in metro-adjacent counties. Other variables held constant at means. Vertical bars represent $95 \%$ CI. 


\subsubsection{Manufacturing}

Continuing to counter hypotheses, manufacturing had a generally non-significant relationship with economic outcomes and this effect was quite stable across all levels of HHI (Figures 11 to 14). These results suggest HHI has limited impact on the relationship between manufacturing employment share and economic outcomes in non-metropolitan counties.

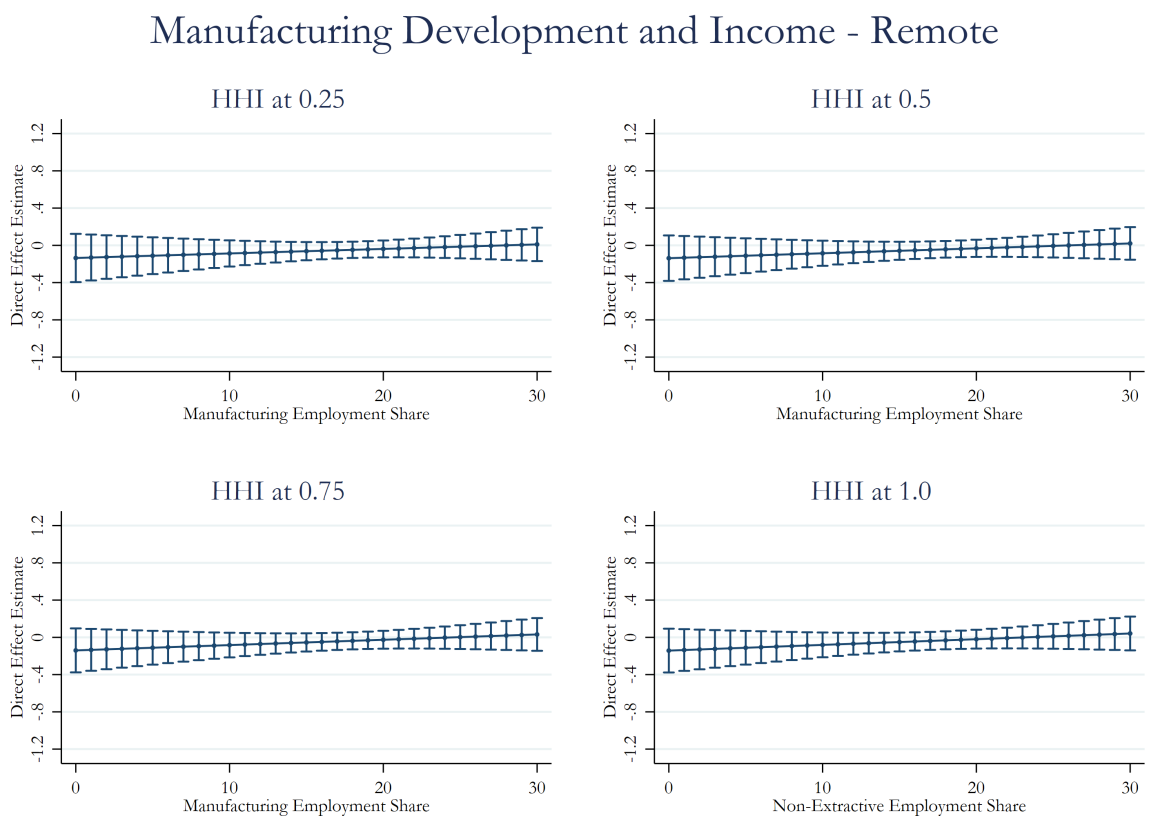

Figure 11: Predicted marginal direct relationships for per capita income across constrained ranged of manufacturing employment share in remote counties. Other variables held constant at means. Vertical bars represent $95 \%$ CI. 


\section{Manufacturing Development and Income - Metro Adjacent}
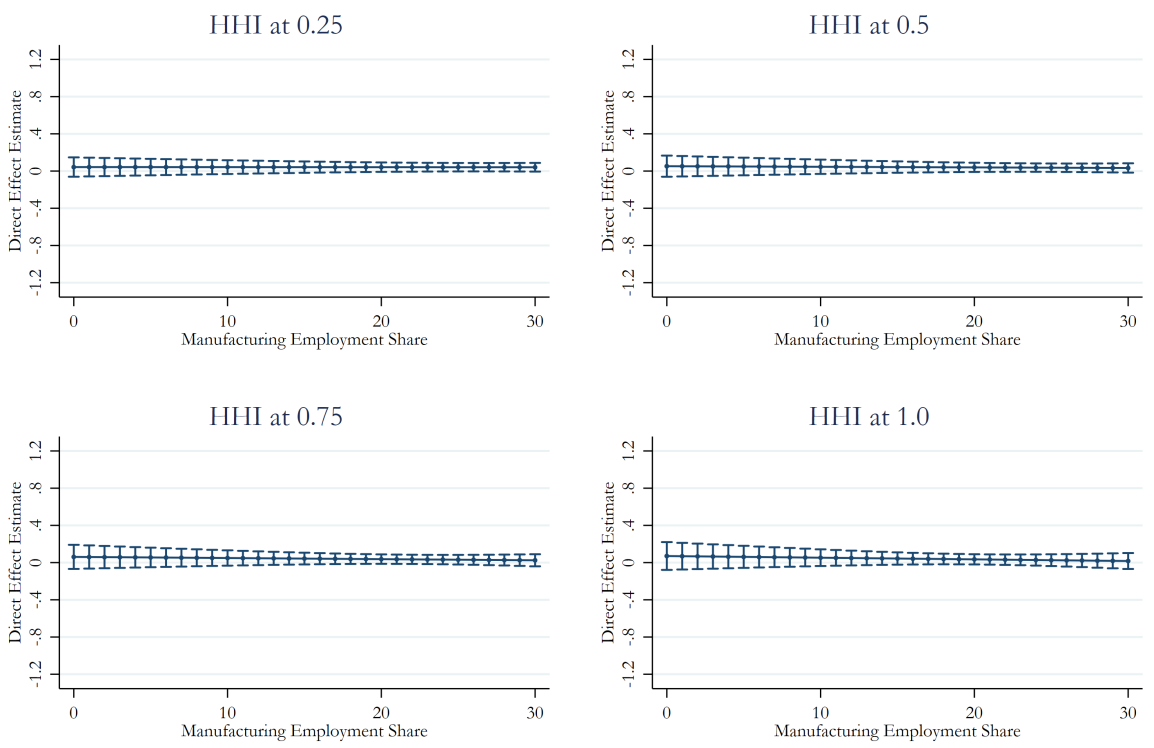

Figure 12: Predicted marginal direct relationships for per capita income across constrained ranged of non-extractive employment share in metro-adjacent counties. Other variables held constant at means. Vertical bars represent $95 \%$ CI.
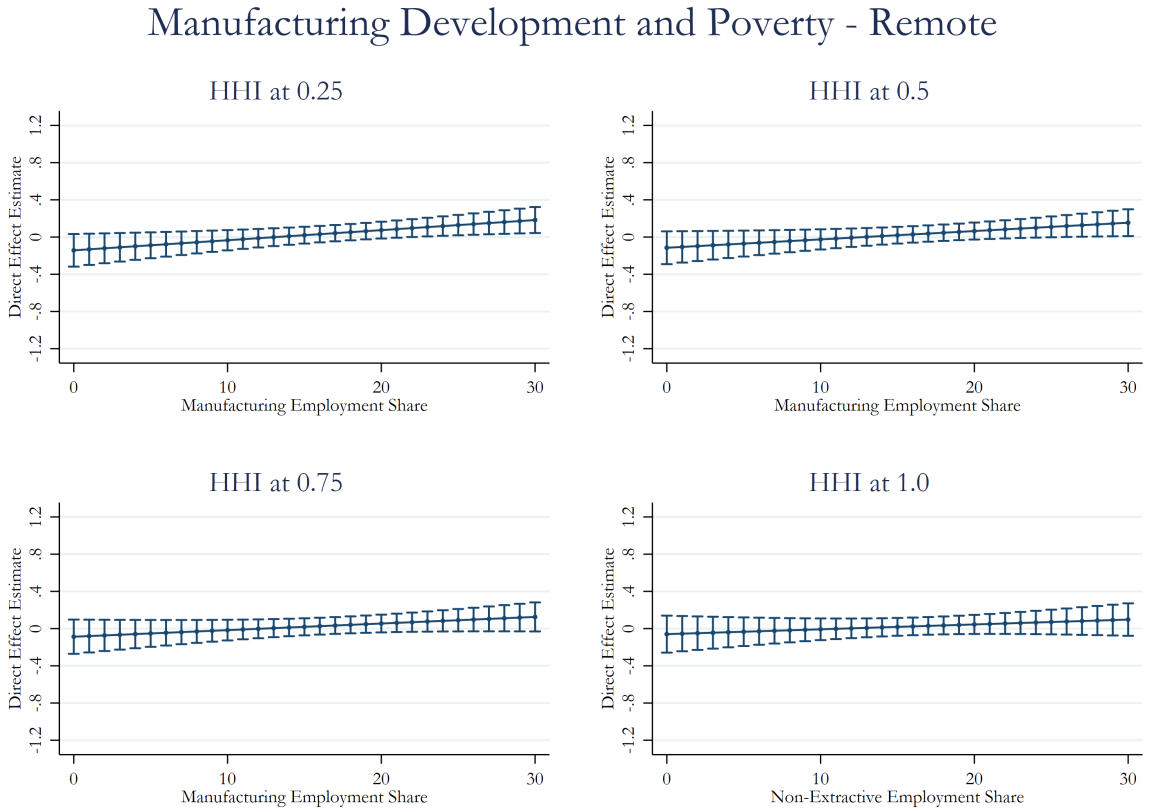

Figure 13: Predicted marginal direct relationships for poverty across constrained ranged of manufacturing employment share in remote counties. Other variables held constant at means. Vertical bars represent $95 \%$ CI. 


\section{Manufacturing Development and Poverty - Metro Adjacent}
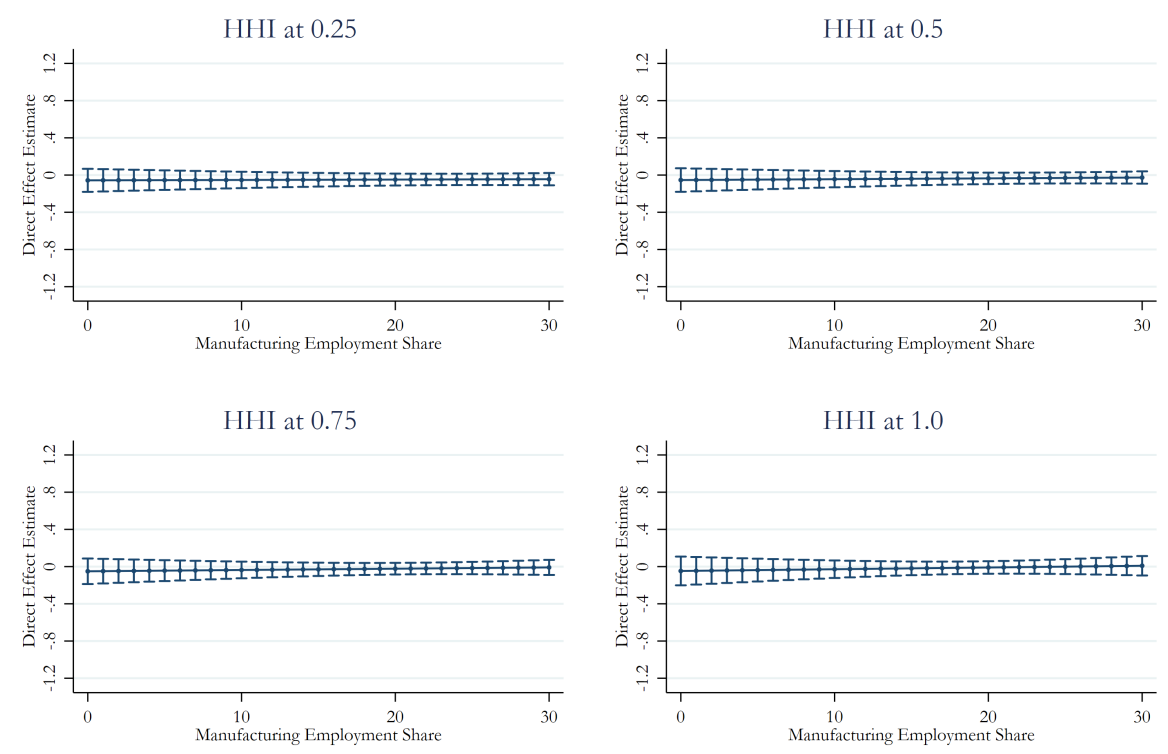

Figure 14: Predicted marginal direct relationships for poverty across constrained ranged of manufacturing employment share in metro-adjacent counties. Other variables held constant at means. Vertical bars represent $95 \%$ CI.

\section{Discussion}

In this paper, we tested a key mechanism of natural resource dependence advanced by Mueller (Forthcoming) - market concentration. Looking at the county level, we found market concentration does interact with the non-linear relationship between both forms of natural resource development and economic outcomes, although there was far more evidence for the case of extraction. Although variable between remote and adjacent counties, higher levels of market concentration were associated with fewer initial benefits of specialization and a more steady relationship between the level of specialization and economic outcomes. Importantly, when looking at our figures, we also find that the drop off of benefits at high levels of specialization (e.g., over-specialization) was lower in high HHI contexts, indicating a flatter relationship across the range of development in highly concentrated markets. The reason for this lack of a drop off at high levels of specialization in high HHI contexts may be due to the ability of firms to exert control over a concentrated market-but future research is required to determine if this is the case. Further, although our models are robust and theory-derived, the inability to define market concentration where we observe no job vacancies posted in the relevant sectors with a county means that we could not include all counties in our 
models that include concentration. It will be important for future work to find a way to generate more complete measures of market concentration so that our results may be validated.

Our base models in this study find similar results to Mueller (2021a) in the case of extraction, but non-extractive development was more dissimilar than similar with the relationship only being consistently different than zero in one of the four scenarios. Unlike Mueller (2021a) — where non-extractive development generally had negative associations with outcomes at low levels of specialization, which either persisted or diminished at high levels - in three of four scenarios we find no relationship between specialization in non-extractive development and economic outcomes. The trends in changing coefficients were similar, but the standard errors consistently crossed zero. To be clear, this does not provide evidence that specialization in non-extractive development is good for rural economies; specialization does not appear to have reduced poverty or increased incomes. However, the difference between the results requires future research attention. This study utilized a different study period and employment share dataset than Mueller (2021a), so continued research is needed to establish a consensus on the relationship between non-extractive natural resource development and economic outcomes. Important first steps in this will be the separate consideration of real estate development and tourism, as well as the estimation of region-specific models.

Regardless of the reason, from this study we can confirm that Mueller (2021a)'s initial hypothesis that extractive and non-extractive development should have similar curves of over-specialization was overly simplistic. Although both forms of development may be inherently exploitative of rural labor markets, share the spatial contradiction, and thus share similar mechanisms, we should not expect their specialization curves to be identical. This difference between the two forms of development stems from the fact that although these sectors share many factors, they have important differences; key among these is the poor nature of the jobs available in the non-extractive versus the extractive sector (Green, 2017). It appears clear that future research should do as we have done here, and hypothesize a clear curve of over-specialization for extraction, and a more nuanced, yet still nonlinear, relationship for non-extractive natural resource development.

It should be noted we find no notable effect of market concentration on the impact of manufacturing specialization in any of our scenarios. Manufacturing, which had generally non-significant associations with economic outcomes in our base models, also had limited effect in our models of market concentration. This finding supports the notion that natural-resource related forms of 
economic development, particularly extraction, have a relationship with rural labor markets unique from other sectors, such as manufacturing. This finding supports arguments made by Mueller (2021b) regarding both the role of market concentration in natural resource dependency, as well as the argument that both extractive and non-extractive forms of development have shared mechanisms by which they impact rural economic prosperity.

In sum, we have shown that market concentration plays a unique role in the relationship between natural resources and economic prosperity that we do not see for manufacturing. By using robust analytic techniques and accounting for spatial spillovers, we have confirmed some of the earlier findings of Mueller (2021a), while also finding support for prior arguments suggesting market concentration was a major factor in natural resource dependence. Market concentration is an under-explored issue across all research, but it is particularly lacking among rural scholars. It is important that those focused on the rural United States account for this phenomenon in their theory and research.

\section{References}

Azar, J., Marinescu, I., and Steinbaum, M. (2020a). Labor Market Concentration. Journal of Human Resources. Forthcoming.

Azar, J., Marinescu, I., Steinbaum, M., and Taska, B. (2020b). Concentration in US labor markets: Evidence from online vacancy data. Labour Economics, 66:101886.

Benmelech, E., Bergman, N., and Kim, H. (2020). Strong Employers and Weak Employees: How Does Employer Concentration Affect Wages? Journal of Human Resources. Forthcoming.

Bowie, N. E. (1988). Fair markets. Journal of Business Ethics, 7(1/2):89-98.

Brooks, M. M. (2019). The advantages of comparative LISA techniques in spatial inequality research: Evidence from poverty change in the United States. Spatial Demography, 7(2-3):167-193.

Brown, D. L. and Schafft, K. A. (2019). Rural people and communities in the 21st century: Resilience and transformation: Second Edition. Medford, MA: Polity.

Bureau of Economic Analysis (2020). Local area personal income methodology [dataset]. Technical report. 
Burt, R. S. (1997). The contingent value of social capital. Administrative Science Quarterly, 42:339-442.

Cameron, A. C. and Miller, D. L. (2015). A practitioner's guide to cluster-robust inference. Journal of Human Resources, 50(2):317-372.

Chi, G. and Zhu, J. (2019). Spatial regression models for the social sciences. Thousand Oaks, CA: Sage.

Crabtree, J. (2016). A different path for rural american. Journal of Economics and Sociology, $75(3): 605-622$.

Deller, S. (2010). Rural poverty, tourism and spatial heterogeneity. Annals of Tourism Research, $37(1): 180-205$.

Deller, S. C., Lledo, V., and Marcouiller, D. W. (2008). Modeling regional economic growth with a focus on amenities. Review of Urban 6 Regional Development Studies: Journal of the Applied Regional Science Conference, 20(1):1-21.

Deller, S. C. and Schreiber, A. (2012). Mining and community economic growth. Review of Regional Studies, 42(2).

Deller, S. C., Tsai, T.-H., Marcouiller, D. W., and English, D. B. (2001). The role of amenities and quality of life in rural economic growth. American Journal of Agricultural Economics, 83(2):352365.

Douglas, S. and Walker, A. (2017). Coal mining and the resource curse in the eastern United States. Journal of Regional Science, 57(4):568-590.

Duncan, C. M. (2014). Worlds apart: Poverty and politics in rural America, Second Edition. New Haven: Yale University Press.

Eckert, F., Fort, T. C., Schott, P. K., and Yang, N. J. (2020). County business patterns database [dataset]. http://www.fpeckert.me/cbp/ Accessed on 1/8/2020.

Economic Research Service (2020). Documentation of rural urban continuum codes. Technical report, United States Department of Agriculture. 
English, D. B., Marcouiller, D. W., and Cordell, H. K. (2000). Tourism dependence in rural America: Estimates and effects. Society $\&$ Natural Resources, 13(3):185-202.

Fowler, C. S. and Jensen, L. (2020). Bridging the gap between geographic concept and the data we have: The case of labor markets in the usa. Environment and Planning A: Economy and Space, page 0308518X20906154.

Freudenburg, W. R. (1992). Addictive economies: Extractive industries and vulnerable localities in a changing world economy. Rural Sociology, 57(3):305-332.

Freudenburg, W. R. and Wilson, L. J. (2002). Mining the data: Analyzing the economic implications of mining for nonmetropolitan regions. Sociological Inquiry, 72(4):549-575.

Ghose, R. (2004). Big sky or big sprawl? Rural gentrification and the changing cultural landscape of missoula, montana. Urban Geography, 25(6):528-549.

Gibbons, S. and Overman, H. G. (2012). Mostly pointless spatial econometrics? Journal of Regional Science, 52(2):172-191.

Glenna, L. L. and Cahoy, D. R. (2009). Agribusiness concentration, intellectual property, and the prospects for rural economic benefits from the emerging biofuel economy. Southern Rural Sociology, 23(2):111-129.

Green, G. (2017). The opportunities and limits of economic growth. In Tickamyer, A. R., Sherman, J., and Warlick, J., editors, Rural Poverty in the United States, pages 416-438. Columbia University Press: New York, NY.

Hafiz, H. (2019). Labor antitrust's paradox. The University of Chicago Law Review, 86:381-411.

Harrigan, R. K. (1984). Formulating vertical integration strategies. The Academy of Management Review, 9(3):638-652.

Hart, L. and O'Connell, J. (2006). European dairy cooperative strategies: Horizontal integration versus diversity. In Karantininis, K. and Nilsson, J., editors, Vertical Markets and Cooperative Hierarchies, pages 1-16. Springer Academic Publishers: Netherlands.

Harvey, D. (2018:1982). The Limits to Capital. New York, NY: Verso books. 
Harvey, M. H. (2017). Racial inequalities and poverty in rural America. In Tickamyer, A. R., Sherman, J., and Warlick, J., editors, Rural Poverty in the United States, pages 141-167. Columbia University Press: New York, NY.

Heaver, T., Meersman, E., and De Voorde, V. (2001). Co-operation and competition in international container transport: strategies for ports. Maritime Policy $\&$ Management, 28(3):293-305.

Herbert, B. and Pritchard, B. (2004). The changing geographies of power and control in rural service provision: Recent restructuring within the australian tractor dealership system. Australian Geographical Studies, 42(1):18-33.

Hines, J. D. (2010). Rural gentrification as permanent tourism: The creation of the 'New' West Archipelago as postindustrial cultural space. Environment and Planning D: Society and Space, 28(3):509-525.

Isserman, A. M. (2005). In the national interest: Defining rural and urban correctly in research and public policy. International Regional Science Review, 28(4):465-499.

Johnson, K. M. and Lichter, D. T. (2019). Rural depopulation: Growth and decline processes over the past century. Rural Sociology, 84(1):3-27.

Kalleberg, A. L. (2011). Good jobs, bad jobs: The rise of polarized and precarious employment systems in the United States, 1970s-2000s. Russel Sage Foundation: New York.

Krannich, R. S., Gentry, B., Luloff, A., and Robertson, P. (2014). Resource dependency in rural america: Continuities and change. In Bailey, C., Jensen, L., and Ransom, E., editors, Rural America in a Globalizing World, pages 208-225. West Virginia University Press.

Kudelko, J., Wirth, H., Bachowski, C., and Gacek, J. (2015). Horizontal integration in the development strategy of mining companies. Mining Science, 22:101-115.

Lobao, L., Zhou, M., Partridge, M., and Betz, M. (2016). Poverty, place, and coal employment across Appalachia and the United States in a new economic era. Rural Sociology, 81(3):343-386. 
Lobao, L. M., Hooks, G., and Tickamyer, A. R. (2007a). Advancing the sociology of spatial inequality. In Lobao, L. M., Hooks, G., and Tickamyer, A. R., editors, The Sociology of Spatial Inequality, pages 1-28. Albany, NY: SUNY Press.

Lobao, L. M., Hooks, G., and Tickamyer, A. R. (2007b). The sociology of spatial inequality. Albany, NY: SUNY Press.

Lovejoy, S. B. and Krannich, R. S. (1982). Rural industrial development and domestic dependency relations: Toward an integrated perspective. Rural Sociology, 47(3):475-495.

Manson, S., Schroeder, J., Van Riper, D., and Ruggles, S. (2020). IPUMS national historical geographic information system: Version 15.0 [dataset].

Marcouiller, D. W., Kim, K.-K., and Deller, S. C. (2004). Natural amenities, tourism and income distribution. Annals of Tourism Research, 31(4):1031-1050.

Marinescu, I. and Rathelot, R. (2018). Mismatch Unemployment and the Geography of Job Search. American Economic Journal: Macroeconomics, 10(3):42-70.

Mueller, J. T. (2021a). Natural resource dependence and rural american economic prosperity from 2000 to 2015. Economic Development Quarterly.

Mueller, J. T. (Forthcoming). The dual dependency of natural-resource-rich labor markets in contemporary society. Sociological Theory.

Mueller, T. J. (2021b). Defining dependence: The natural resource community typology. Rural Sociology.

Nelson, P. B. and Hines, J. D. (2018). Rural gentrification and networks of capital accumulation-a case study of jackson, wyoming. Environment and Planning A: Economy and Space, 50(7):14731495.

Nelson, P. B., Lee, A. W., and Nelson, L. (2009). Linking baby boomer and hispanic migration streams into rural america-a multi-scaled approach. Population, Space and Place, 15(3):277-293.

Nord, M. and Luloff, A. E. (1993). Socioeconomic heterogeneity of mining-dependent counties. Rural Sociology, 58(3):492-500. 
Perdue, R. T. and Pavela, G. (2012). Addictive economies and coal dependency: methods of extraction and socioeconomic outcomes in West Virginia, 1997-2009. Organization E Environment, $25(4): 368-384$.

Poudyal, N. C., Hodges, D. G., and Cordell, H. K. (2008). The role of natural resource amenities in attracting retirees: Implications for economic growth policy. Ecological Economics, 68(1-2):240248.

Schroeder, J., Pacas, J., and Van Riper, D. (2019). Getting "rural" right: Poverty disparities across two dimensions of rurality. Population Association of America Meeting.

Sherman, J. (2018). Not allowed to inherit my kingdom: Amenity development and social inequality in the rural West. Rural Sociology, 83(1):174-207.

Smith, N. (1984). Uneven development: Nature, capital, and the production of space. New York, NY: Basil Blackwell.

Smith, N. (2011). Uneven development redux. New Political Economy, 16(2):261-265.

Stedman, R. C., Parkins, J. R., and Beckley, T. M. (2005). Forest dependence and community well-being in rural Canada: Variation by forest sector and region. Canadian Journal of Forest Research, 35(1):215-220.

Steinbaum, M. (2019). Antitrust, the gig economy, and labor market power. Law and Contemporary Problems, 82(3):45-64.

Steinbaum, M. and Stucke, Maurice, E. (2019). The effective competition standard: a new standard for antitrust. The University of Chicago Law Review, 86:595-623.

Thiede, B., Kim, H., and Valasik, M. (2018). The spatial concentration of America's rural poor population: A postrecession update. Rural Sociology, 83(1):109-144.

Thiede, B. and Slack, T. (2017). The old versus the new economies and their impacts. In Tickamyer, A. R., Sherman, J., and Warlick, J., editors, Rural Poverty in the United States, pages 231-256. New York, NY: Columbia University Press. 
Thiede, B. C., Brown, D. L., Sanders, S. R., Glasgow, N., and Kulcsar, L. J. (2017). A demographic deficit? Local population aging and access to services in rural america, 1990-2010. Rural sociology, 82(1):44-74.

Ulrich-Schad, J. D. (2018). "We didn't move here to move to Aspen": Community making and community development in an emerging rural amenity destination. Journal of Rural and Community Development, 13(4).

Ulrich-Schad, J. D. and Qin, H. (2018). Culture clash? predictors of views on amenity-led development and community involvement in rural recreation counties. Rural Sociology, 83(1):81-108.

Vega, S. H. and Elhorst, J. P. (2015). The SLX model. Journal of Regional Science, 55(3):339-363.

Weber, M. (1971). Class, status, and party. In Gerth, H. H. and Mills, C. W., editors, From Max Weber: essays in sociology, pages 180-195. Oxford University Press.

Williams, D., Reiter, K. L., Pink, G. H., Holmes, G. M., and Song, P. H. (2020). Rural hospital mergers increased between 2005 and 2016-what did those hospitals look like? Journal of Health Care, 57:1-16.

Winkler, R., Cheng, C., and Golding, S. (2012). Boom or bust? Population dynamics in natural resource-dependent counties. In Kulcsar, L. J. and Curtis, K. J., editors, International handbook of rural demography, pages 349-367. Springer.

\section{Appendix}




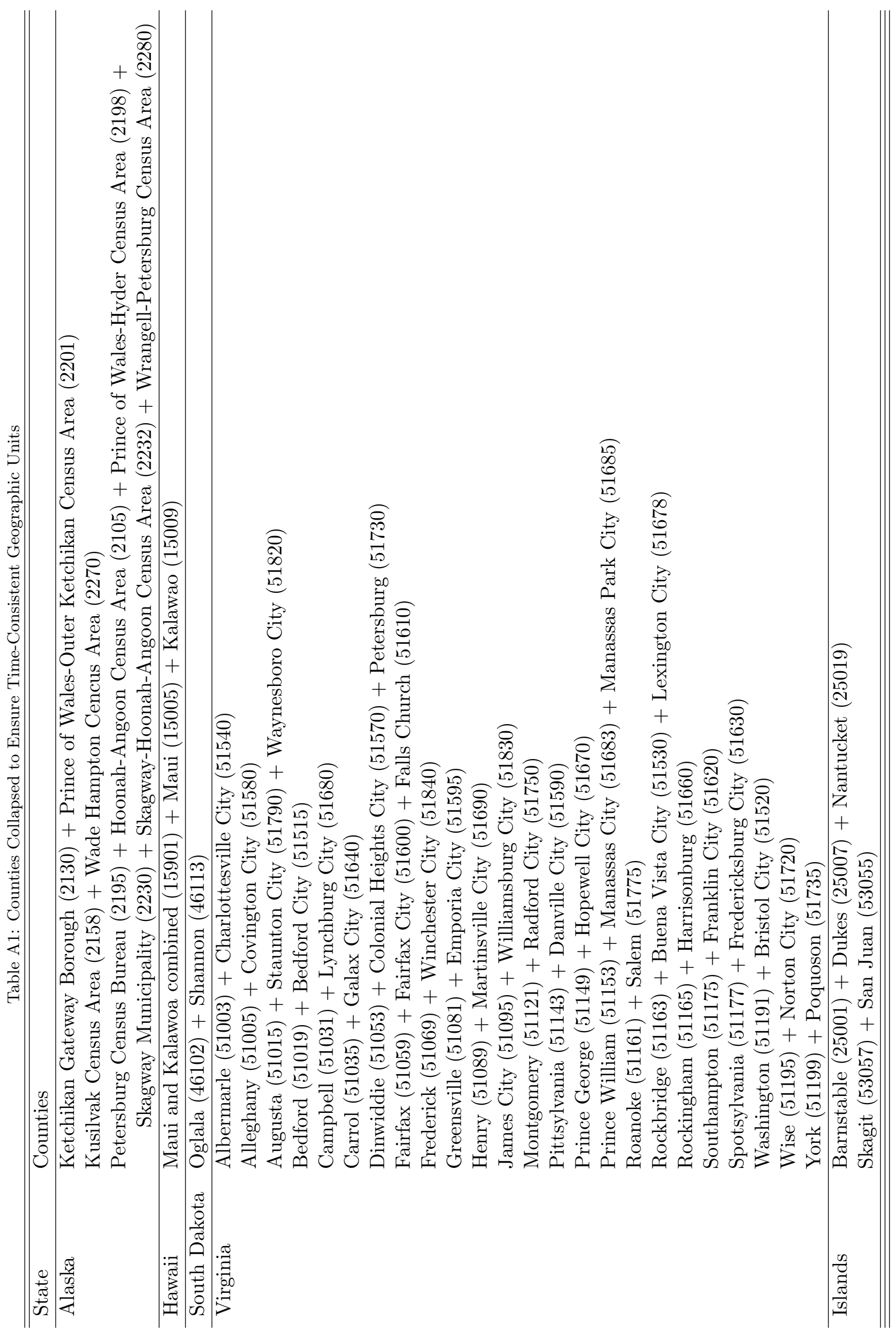


Table A2a: Summary Statistics for Model Variables

\begin{tabular}{lcccc}
\hline \hline & Mean & SD & Min & Max \\
\hline Metro & & & & \\
Per Capita Income to Residents (thousands) & 25.64 & 8.57 & 9.44 & 100.63 \\
Poverty Rate & 14.56 & 5.46 & 2.43 & 44.81 \\
Extractive Employment Share & 0.62 & 1.90 & 0.00 & 44.37 \\
Non-extractive Employment Share & 7.75 & 4.22 & 0.00 & 77.17 \\
Manufacturing Employment Share & 7.46 & 5.75 & 0.00 & 46.70 \\
HHI - Extraction & 0.63 & 0.32 & 0.01 & 1.00 \\
HHI - Non-extractive & 0.19 & 0.22 & 0.00 & 1.00 \\
HHI - Manufacturing & 0.28 & 0.28 & 0.01 & 1.00 \\
Population (thousands) & 235.70 & 505.57 & 0.71 & 10105.72 \\
Percent Over 65 & 15.11 & 3.87 & 3.28 & 55.60 \\
Percent white & 81.08 & 15.14 & 12.62 & 99.80 \\
Percent Black & 10.96 & 13.49 & 0.00 & 78.51 \\
Percent Latino/a & 9.45 & 12.46 & 0.00 & 95.60 \\
\hline$N$ & 1,146 & & & \\
\hline Nonmetro Metro-Adjacent & & & & \\
Per Capita Income to Residents (thousands) & 19.79 & 5.95 & 1.27 & 127.41 \\
Poverty Rate & 17.95 & 6.42 & 0.00 & 53.95 \\
Extractive Employment Share & 1.27 & 2.89 & 0.00 & 36.33 \\
Non-extractive Employment Share & 6.20 & 4.09 & 0.00 & 68.87 \\
Manufacturing Employment Share & 9.85 & 7.91 & 0.00 & 74.28 \\
HHI - Extraction & 0.81 & 0.27 & 0.04 & 1.00 \\
HHI - Non-extractive & 0.34 & 0.27 & 0.00 & 1.00 \\
HHI - Manufacturing & 0.48 & 0.30 & 0.01 & 1.00 \\
Population (thousands) & 29.79 & 23.78 & 0.60 & 189.28 \\
Percent Over 65 & 17.96 & 3.73 & 4.58 & 38.82 \\
Percent white & 84.01 & 17.38 & 3.55 & 100.00 \\
Percent Black & 9.77 & 16.17 & 0.00 & 87.41 \\
Percent Latino/a & 8.05 & 13.59 & 0.00 & 99.18 \\
\hline$N$ & 1,020 & & & \\
\hline \hline
\end{tabular}


Table A2b: Summary Statistics for Model Variables

\begin{tabular}{lcccc}
\hline \hline & Mean & SD & Min & Max \\
\hline Nonmetro Remote & & & & \\
Per Capita Income to Residents (thousands) & 22.81 & 9.95 & 6.69 & 101.14 \\
Poverty Rate & 16.82 & 7.19 & 1.51 & 55.10 \\
Extractive Employment Share & 1.78 & 3.79 & 0.00 & 60.48 \\
Non-extractive Employment Share & 5.80 & 4.78 & 0.00 & 55.61 \\
Manufacturing Employment Share & 6.52 & 7.91 & 0.00 & 86.63 \\
HHI - Extraction & 0.78 & 0.29 & 0.05 & 1.00 \\
HHI - Non-extractive & 0.41 & 0.31 & 0.01 & 1.00 \\
HHI - Manufacturing & 0.55 & 0.32 & 0.03 & 1.00 \\
Population (thousands) & 16.75 & 17.80 & 0.07 & 197.66 \\
Percent Over 65 & 18.82 & 4.96 & 3.79 & 39.16 \\
Percent white & 86.30 & 17.16 & 3.11 & 100.00 \\
Percent Black & 5.59 & 12.93 & 0.00 & 77.46 \\
Percent Latino/a & 8.88 & 14.73 & 0.00 & 95.54 \\
\hline$N$ & 941 & & & \\
\hline Total & & & & \\
Per Capita Income to Residents (thousands) & 22.86 & 8.64 & 1.27 & 127.41 \\
Poverty Rate & 16.36 & 6.50 & 0.00 & 55.10 \\
Extractive Employment Share & 1.18 & 2.94 & 0.00 & 60.48 \\
Non-extractive Employment Share & 6.65 & 4.44 & 0.00 & 77.17 \\
Manufacturing Employment Share & 7.96 & 7.32 & 0.00 & 86.63 \\
HHI - Extraction & 0.72 & 0.31 & 0.01 & 1.00 \\
HHI - Non-extractive & 0.30 & 0.28 & 0.00 & 1.00 \\
HHI - Manufacturing & 0.41 & 0.32 & 0.01 & 1.00 \\
Population (thousands) & 101.79 & 324.13 & 0.07 & 10105.72 \\
Percent Over 65 & 17.17 & 4.49 & 3.28 & 55.60 \\
Percent white & 83.62 & 16.66 & 3.11 & 100.00 \\
Percent Black & 8.94 & 14.45 & 0.00 & 87.41 \\
Percent Latino/a & 8.82 & 13.57 & 0.00 & 99.18 \\
\hline$N$ & 3,107 & & & \\
\hline \hline
\end{tabular}




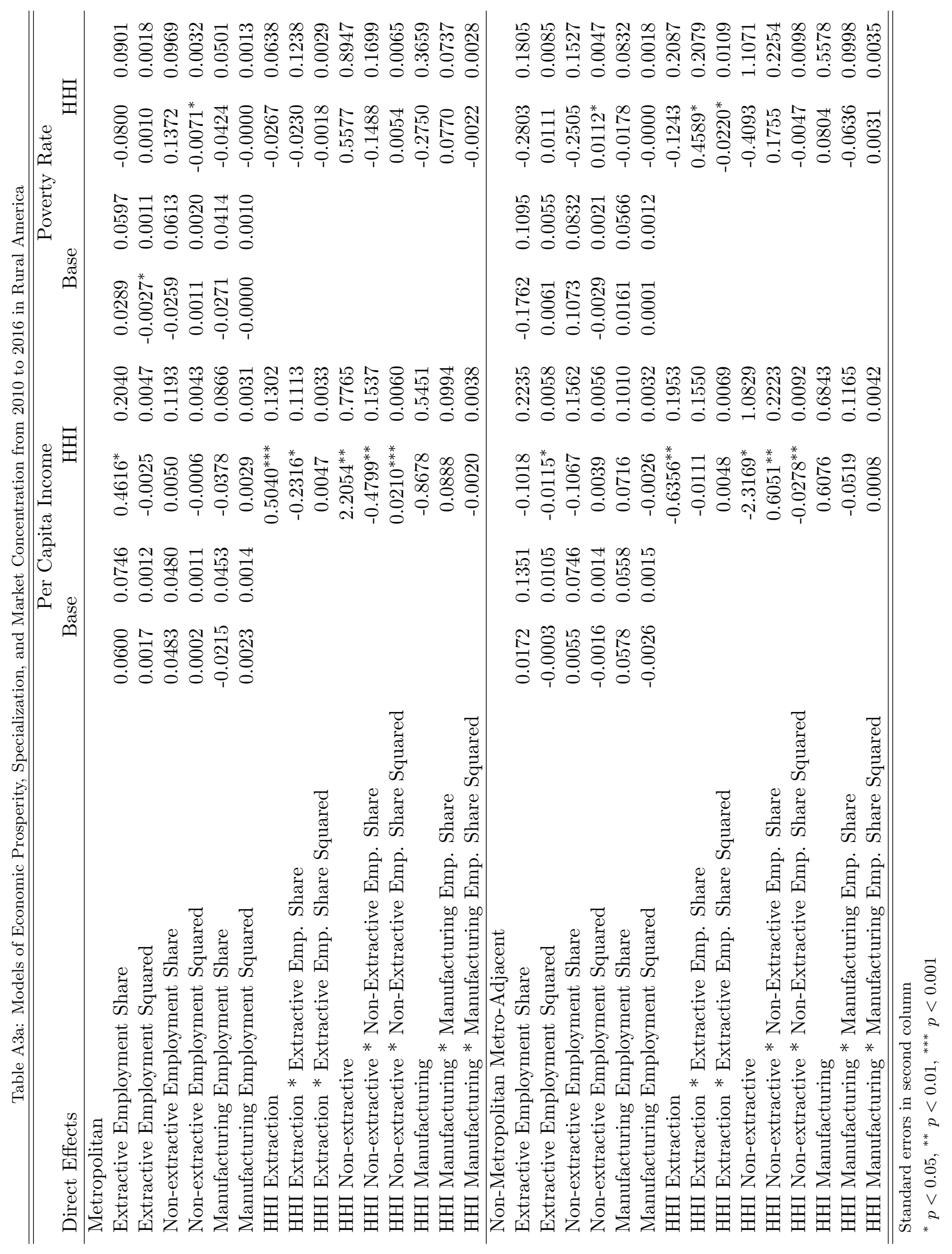




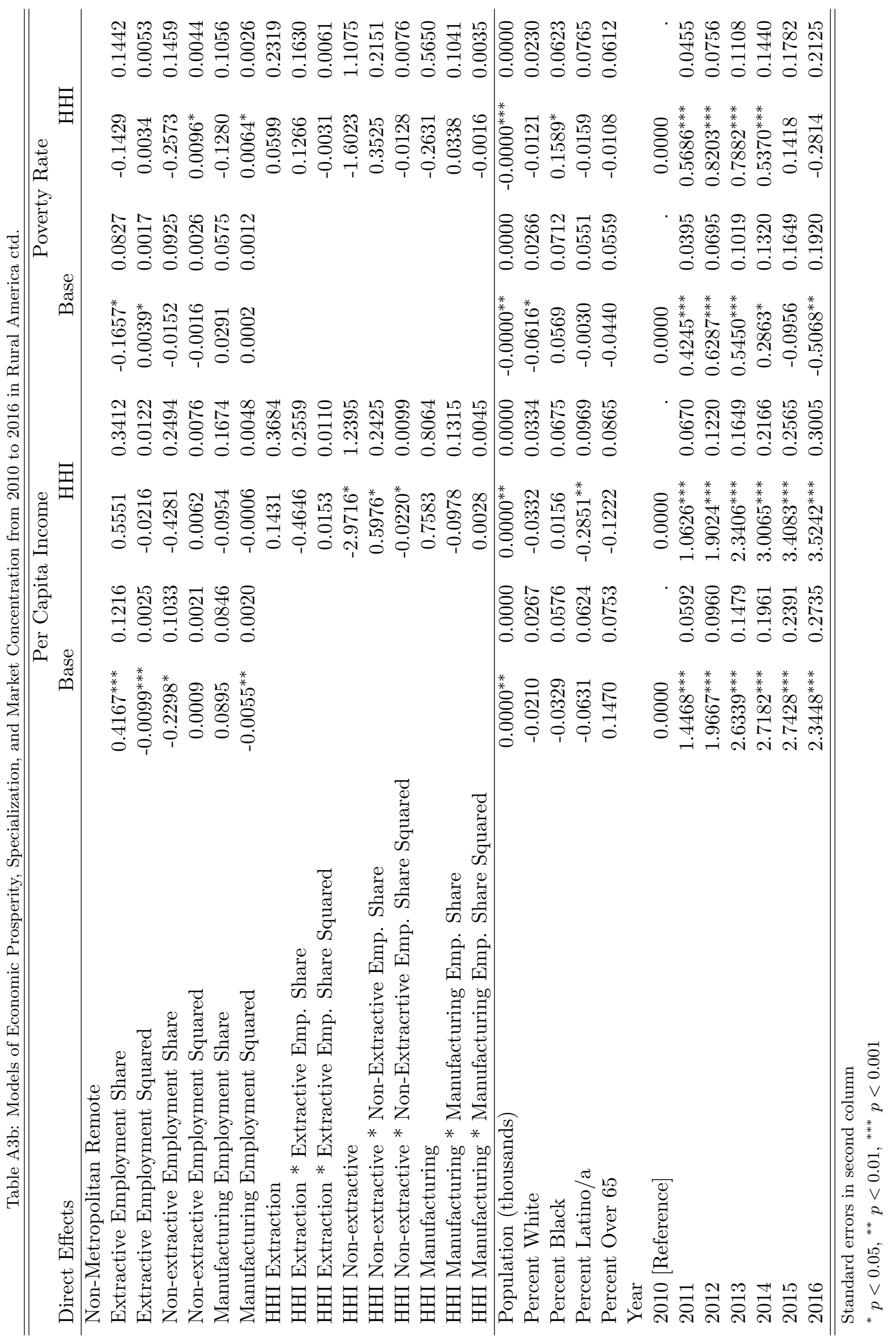




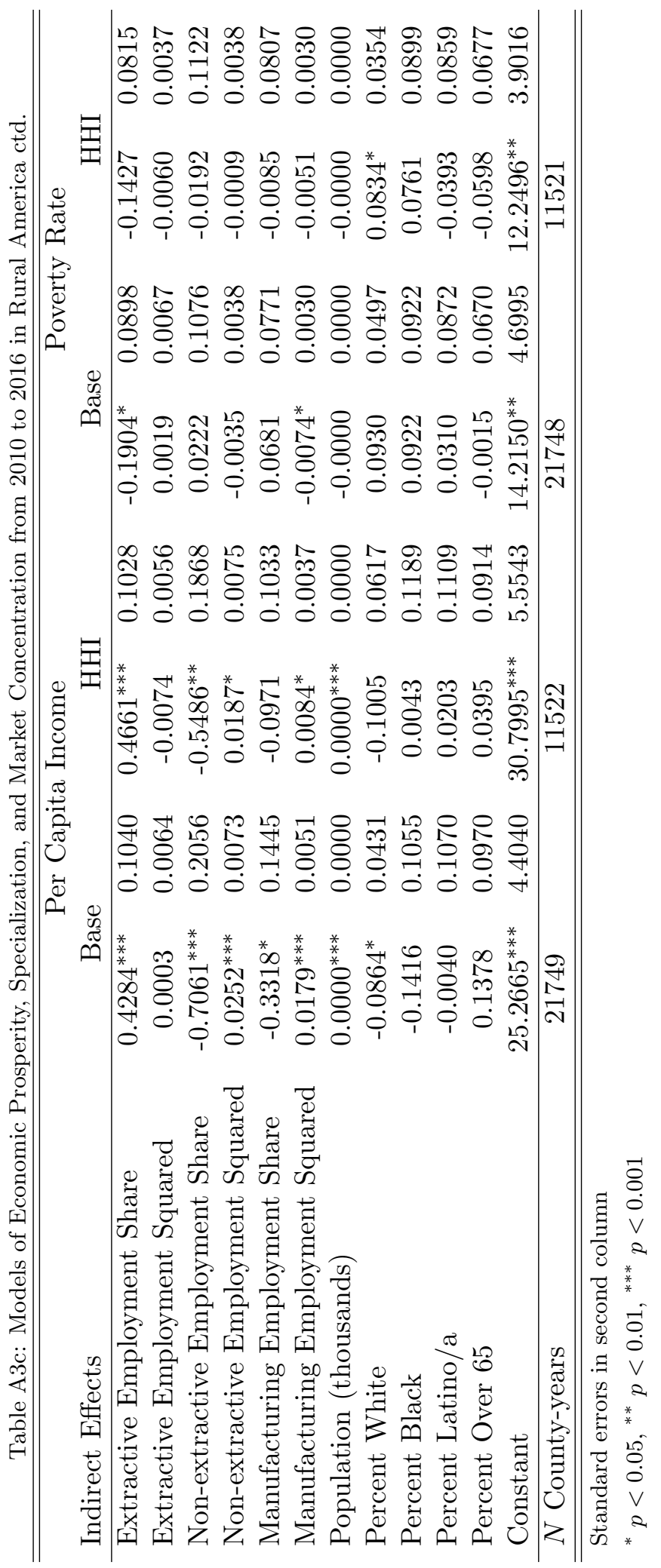

